University of Nebraska - Lincoln

DigitalCommons@University of Nebraska - Lincoln

US Army Research

U.S. Department of Defense

2003

\title{
Military Leadership: A Context Specific Review
}

Leonard Wong

Strategic Studies Institute, U.S. Army War College, 122 Forbes Avenue, Carlisle, PA

Paul Bliese

Walter Reed Army Institute of Research, USA

Dennis McGurk

Walter Reed Army Institute of Research, USA

Follow this and additional works at: https://digitalcommons.unl.edu/usarmyresearch

Part of the Operations Research, Systems Engineering and Industrial Engineering Commons

Wong, Leonard; Bliese, Paul; and McGurk, Dennis, "Military Leadership: A Context Specific Review" (2003). US Army Research. 16.

https://digitalcommons.unl.edu/usarmyresearch/16

This Article is brought to you for free and open access by the U.S. Department of Defense at DigitalCommons@University of Nebraska - Lincoln. It has been accepted for inclusion in US Army Research by an authorized administrator of DigitalCommons@University of Nebraska - Lincoln. 


\title{
Military leadership: A context specific review ${ }^{\text {ts }}$
}

\author{
Leonard Wong ${ }^{\mathrm{a}, *}$, Paul Bliese ${ }^{\mathrm{b}}$, Dennis McGurk ${ }^{\mathrm{b}}$ \\ ${ }^{a}$ Strategic Studies Institute, U.S. Army War College, 122 Forbes Avenue, Carlisle, PA 17013-5244, USA \\ ${ }^{\mathrm{b}}$ Walter Reed Army Institute of Research, USA
}

Accepted 25 August 2003

\begin{abstract}
The purpose of this article is to review the literature on military leadership and highlight research opportunities for leadership scholars. The review uses a context specific approach and turns to a simplified version of Hunt's (Hunt, J. G. (1991). Leadership: A new synthesis. Newbury Park, CA: Sage) extended multilevel leadership model as a template to examine the many facets of military leadership. The military leadership literature is stratified into the systems, organizational, and direct levels of leadership with an examination of studies on the critical tasks and individual capabilities required at each level. Additionally, studies on organizational culture and effectiveness at each level are addressed. The article emphasizes that the military is undergoing substantial change as it adjusts to the changing nature of war and a fluid world situation. Based on trends in the military, the review concludes with several general recommendations for future research.

Published by Elsevier Inc.
\end{abstract}

Keywords: Leadership; Military; Strategic leadership; Army; Transformational; Joint

\section{Introduction}

Reviewing the field of "military leadership" appears to be a fairly straightforward endeavor. After all, leadership and the military are practically inseparable. For example, the U.S. Army's official vision statement boldly states, "We are about leadership; it is

is The views of the authors do not necessarily reflect the positions of the U.S. Department of the Army or the U.S. Department of Defense.

* Corresponding author. Tel.: +1-717-245-3010; fax: +1-717-245-3820.

E-mail address: leonard.wong@carlisle.army.mil (L. Wong). 
our stock in trade, and it is what makes us different" (U.S. Army, 1999a, p. 7). Military notables such as H. Norman Schwarzkopf, Sun Tzu, George S. Patton, Dwight D. Eisenhower, and Robert E. Lee are synonymous with leadership. While the academic leadership community was busy questioning whether leadership even made a difference (Pfeffer, 1977) or cautioning about the romance of leadership (Meindl \& Ehrlich, 1987), cadets at West Point continued to recite the timeless refrain that "the commander is responsible for everything the unit does or fails to do" (U.S. Army, 1990a, paragraph 2.6).

What makes a review of military leadership challenging, however, is the need to clearly define what does and what does not constitute "military leadership research." In doing so, it is useful to differentiate between two complementary ways in which military leadership research can be defined. The first alternative is to focus on studies that use military samples to test theories that have applicability across a broad range of organizations - or what Blair and Hunt (1986) call a context-free orientation. For instance, transformational leadership (Bass, 1998) may be examined within a military context; however, transformational leadership as a construct is clearly applicable to organizations other than the military. Many leadership theories have been applied to military contexts and so there exists considerable military leadership research of this nature (e.g., Csoka \& Bons, 1978; Deluga, 1991; Roush \& Atwater, 1992).

A second way to define military leadership research is to consider the unique characteristics of the military, and focus on studies that attempt to understand the nature of leadership within this context. This approach, what Blair and Hunt (1986) call a context-specific orientation, requires more in-depth knowledge of the military and the issues facing the military. As such it is likely to capture more of the true essence of what constitutes military leadership.

Ideally, an integrated review of military leadership will encompass both elements. With regard to the first approach, it is clearly important to understand how broader leadership theories operate when applied to military samples. For instance, a question such as, "Is extroversion an important trait for military leaders to possess?" may be theoretically and practically important. More often than not, however, answers to questions about the generalizability of leadership theory require in-depth knowledge of military leadership. Thus, we take the position that a review of military leadership will be of greater value to leadership researchers if we focus on the characteristics of modern military leadership and the corresponding implications for leadership theory. That is, instead of providing a detailed review of leadership studies that have used the military as a sample, we focus primarily on a context-specific approach of military leadership and discuss the implications for understanding and furthering leadership research. Where possible, we also integrate findings from studies that have tested the generalizability of leadership theory using military samples. Our goal is to produce a manuscript that helps articulate what we see as being the key research needs in military leadership. We hope that in so doing, we will provide a resource for leadership researchers who wish to learn more about leadership issues facing the current military. 
In terms of structure of the article, we begin by discussing several key organizational attributes associated with the U.S. military. ${ }^{1}$ Second, we introduce Hunt's (1991) extended multilevel leadership model as a framework to examine military leadership. Hunt's model is extremely useful as it posits three leadership levels - systems, organizational, and directwith tasks, capabilities, and other leadership aspects noted at each level. The model provides a systematic approach for analyzing the many facets of military leadership. Third, with the model serving as a template, we then review the military leadership literature. Hunt's model helps categorize the extant military leadership research and also highlights areas where the absence of findings calls for additional research. To aid in assessing the recent military leadership literature, each leadership level includes a figure summarizing the literature and also some research opportunities. We conclude with a discussion on some general trends in the military that deserve leadership researcher attention.

\subsection{Key organizational characteristics}

A discussion of the military begins by noting that the military is far from the monolithic society often held in stereotypes. The military actually consists of a diverse collection of organizations, roles, cultures, and people. For example, the U.S. military contains three professions: army, maritime, and aerospace (Snider \& Watkins, 2002). These professions are generally (but not wholly) contained in the Departments of the Army, Navy, and Air Force. Each profession has its own culture and, hence, its own unique aspects of leadership. Additionally, "military" may refer to people wearing the uniform all the time (the active duty forces), part of the time (the reserves and national guard), or none of the time (defense employees and military families).

In terms of size, the number of people in the military is huge. In the U.S. alone, there are 1.37 million military men and women in uniform (not including 1.28 million people in the reserves). Contrast this with other organizations that have had context specific leadership studies - 750,000 U.S. Postal System employees, 800,000 full-time U.S. law enforcement officers, or 590,937 full-time U.S. university or college faculty members. The size of the military means that leaders (even rather junior ones) often command large numbers of subordinates, and thus leadership at all levels tends to have a large impact in terms of personnel.

In terms of organizational form, the military is unquestionably traditional. There is a clear delineation of power across hierarchical levels and clear prescriptions about how leaders and subordinates are expected to interact. Using Gordon's (2002) terminology, the military has both very clear "surface-level structures" and very clear "deep structures" defining power arrangements. For instance, through the use of rank insignia, surface-level power is easily identified to all members of the system. At the same time, there are deeply entrenched

\footnotetext{
1 Although the topic is military leadership in general, this review focuses largely on military leadership in the United States and relies heavily on U.S. Army examples. This is due to the authors' associations and the majority of military leadership research being conducted on or sponsored by the U.S. Army.
} 
"codes" of behavioral order (deep structures) that extend beyond the official work environment. The clear surface-level and deep power structures permeate nearly every aspect of military leadership at all levels throughout the organization.

The role of the military in world affairs has recently expanded. While many thought that the military's role would be diminished after the fall of the Berlin Wall, the military has been more active in recent years than during the days of the Cold War. Consider, for example, the military's role in the Persian Gulf in the early 1990s, followed by major involvements in Somalia, Haiti, Bosnia, and Kosovo and then back to the Persian Gulf in 2003. The war on terrorism and operations in Iraq, Afghanistan, and the Philippines illustrate the continued use of the military as a key element of national power.

Despite the headline-grabbing high-tech aspects of recent armed conflict, waging war continues to be an intensely human endeavor. The streets of Bosnia, the mountains of Afghanistan, and the deserts of Iraq require "boots on the ground" to achieve victory. As a result, the military relies on leaders, not managers, program directors, or supervisors, to accomplish its primary mission.

Thus, culturally, leadership was and continues to be a mainstay of the military. Long before leadership became a topic of discussion in the corporate, academic, or even public realm, militaries have been enamored by leadership (e.g., Sun Tzu, 500 BC). The military emphasizes the importance of leadership and strives to develop leaders through formal education, operational assignments, and self-development. For example, officers in the U.S. Army can expect to spend 3 years of a 20-year career in Army schools developing the leader competencies and skills needed for the next level of leadership.

Finally, the U.S. military is much like other large public sector organizations in that it has tendencies toward a hierarchical bureaucracy and must remain responsive to the American people. It differs significantly, however, in that the military ultimately exists to fight and win the nation's wars. At the lowest level, military leadership can be the difference between life and death for many people. At the highest level, the survival of our nation relies upon the leaders in the military. As such, the military is a "greedy institution" (Segal, 1988) with an all-consuming nature that demands nearly all the attention, time, energy, and commitment from its members.

To summarize so far, the military is unique in that it is a huge, diverse, organization that plays a key role in both the nation and the world. It is a traditionally hierarchical institution that finds itself in an uncertain, volatile world executing missions with very high consequences.

\subsection{Hunt's (1991) extended multilevel leadership model}

Hunt's (1991) extended multilevel leadership model provides an excellent template for systematically reviewing leadership research within the military. Hunt's model is based upon Jaques' theory of stratified systems (Jaques, 1976, 1989; Jaques \& Clement, 1991), and brings in notions of the environment and organizational factors across levels of the organization ranging from the strategic level down to direct face-to-face leadership. Fig. 1 shows a simplified version of the extended multilevel leadership model. 


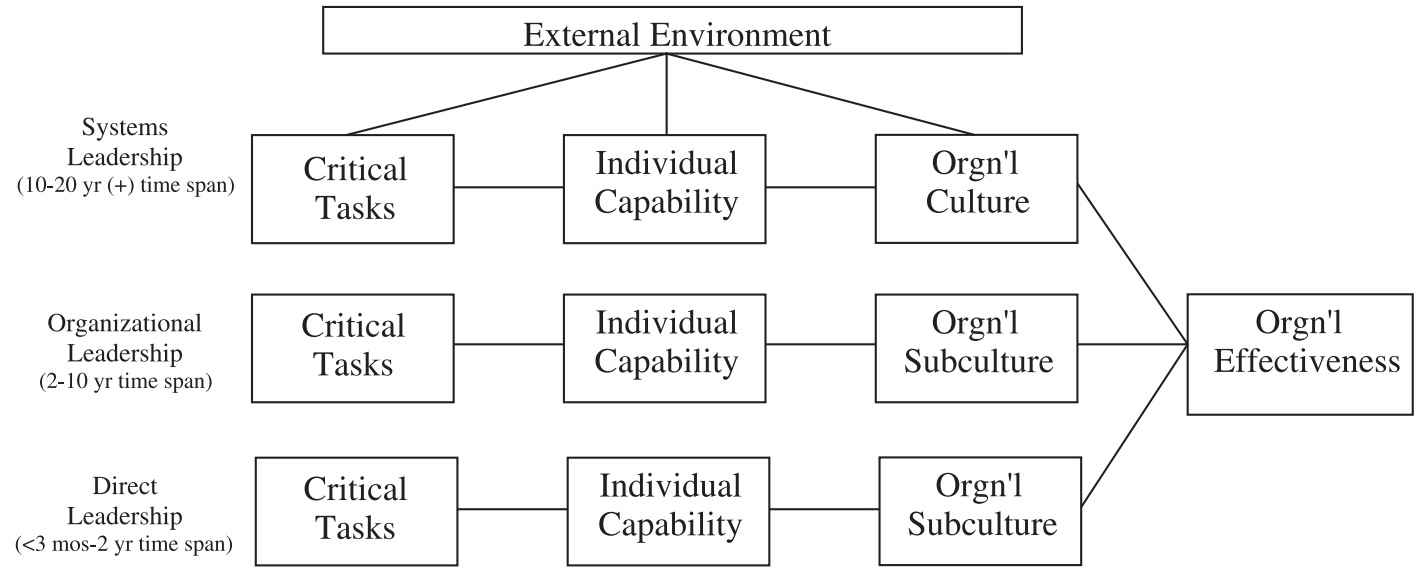

Fig. 1. Simplified version of the extended multilevel leadership model (Hunt, 1991).

Arguing that traditional leadership models are too narrow and restrictive, Hunt advocates a pragmatic perspective concerning leadership knowledge orientation and develops his model across organizational levels. The multilevel leadership model differs from mainstream leadership models in three general ways. First, it has a hierarchical as opposed to a bottom-level, face-to-face emphasis. That is, the model focuses more on the role of leaders to command large groups of followers than it does on the direct dyadic relations among leaders and supervisors. Second, the model has a reliance on longer term temporal aspects than do other models. Stated differently, the model is interested in determining how leadership affects the long-term viability of the organization and it recognizes that leadership at different levels have different time horizons. Third, the model stresses a critical, pluralist approach to gaining, using, and assessing leadership knowledge. A pluralist approach seeks to avoid the objectivist-subjectivist extremes in dealing with underlying assumptions.

At a broad level, the model recognizes that leadership at different levels requires varying degrees of cognitive complexity and differential time-horizon foci. However, one of the most useful aspects of the model is that it incorporates these broad notions into the critical tasks and individual capabilities required at each level of leadership. Critical tasks are the direct product of the key mission, strategy, and organizational design elements unique to each level of leadership. Individual capabilities capture the various leader background factors, preferences, capabilities, and skills at each level.

In addition to critical tasks and individual capabilities, the model considers the impact of external environments and the influence of subcultures/climates on leadership. Finally, the model discusses the notion of performance at the various levels of leadership. This latter point acknowledges that there are differing notions of organizational effectiveness at each level.

The extended multilevel leadership model is especially useful in a review of military leadership for several reasons. First, the model emphasizes both the vertical and temporal aspects of leadership that go beyond the horizontal face-to-face interactions at the lower levels of the organization. In an organization as diverse as the military with leaders ranging 
from sergeants to generals, it is critical to explicitly consider how leadership differs across levels. It is also important to recognize (as the model does) that leadership in the military extends far beyond face-to-face interactions. This fact is recognized by other researchers as well. For instance, in discussing charismatic leadership in the Israeli army, Shamir, Zakay, Breinin, and Popper (1998) note that charismatic "leader behaviors... are not directed at individual subordinates or followers. Rather, they are ambient behaviors that are either directed at the unit as a whole (for instance, emphasizing the collective identity) or at no one in particular (for instance, leaders self-sacrifice)." (p. 392). The critical point is that many leader behaviors go beyond face-to-face interactions, yet the behaviors have a large impact on the units the leader commands in terms of defining a leadership climate.

The second reason why Hunt's (1991) extended leadership model provides a valuable framework for summarizing military leadership is that the model's use of systems, organizational, and direct leadership levels generally parallels the military's stratification of warfare. The three levels of war are the strategic, operational, and tactical levels (U.S. Army, 2001a). At the strategic level, national policy is at stake and national resources are used to accomplish strategic military objectives derived from National Command Authority guidance. At the operational level, major operations and campaigns are fought. This level links the tactical employment of forces to strategic objectives. Finally, it is at the tactical level that battles and engagements are fought. The tactical level, like the direct leadership level, is the realm of close combat. The extended multilevel leadership model corresponds well to the military's delineation of levels in warfare, doctrine, leader development, and command.

Finally, the model provides a useful means of categorizing the various existing studies on military leadership. By moving beyond the direct level of leadership and including leader capabilities and critical tasks, the model presents a method to recognize potential gaps in the military leadership research literature as well as underscoring ways in which military leadership studies may differ from more generic leadership studies.

In the following section, we apply the structure of Hunt's extended leadership model to the three levels of military leadership. While leadership in the military is exercised by both commissioned officers and noncommissioned officers (sergeants), this review focuses mainly on officers at the upper two levels. At the direct level of leadership, the impact of noncommissioned officers is considered.

\section{Systems leadership domain}

Systems level leaders operate at the apex of organizations. According to Hunt (1991), leadership at this level is characterized by operating in volatile, complex, and ambiguous circumstances. These high-level leaders must interface across different societal cultures in the external environment while coordinating organizational systems across these different cultures. Their domain takes them to the highest national and worldwide levels as they interact with high-level political officials. In the military, the system level leaders interfacing with the external environment are the three- and four-star flag officers. They usually have over 30 years experience in the military and either command large numbers of troops (e.g., 
General Franks commanded nearly 300,000 troops during Operation Iraqi Freedom) or are responsible for extremely complex and far-reaching aspects of the military institution (e.g., managing the US\$108 billion Navy budget).

The systems level military leadership literature discussed in the following paragraphs are summarized in Fig. 2. The figure serves as a guide to matching existing studies to Hunt's (1991) model in addition to highlighting research opportunities presented by gaps in the literature.

\subsection{External environment}

The extended multilevel leadership model begins with an examination of the external environment facing these leaders at the highest levels of leadership. Hunt divides the environment into two partially overlapping parts: the general and specific environments. The general environment includes the socioeconomic, educational, legal-political, and cultural aspects that usually operate within a specific geographic area. The specific environment is comprised of the suppliers, distributors, government agencies, and competitors with which an organization must interact.

For systems level leaders in the military, the recent debate on civil-military relations spans both the general and specific environment. Although this is usually the realm of

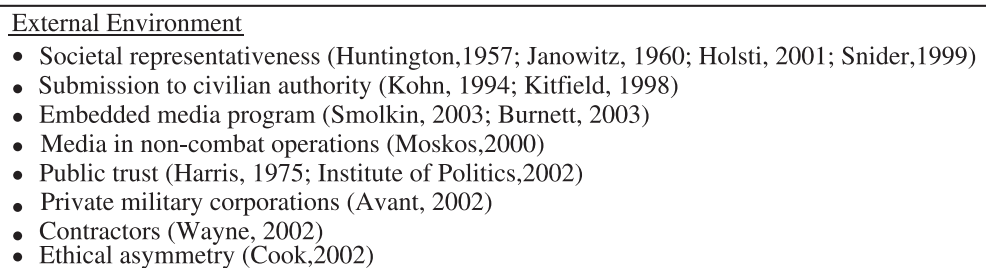

Systems Level Critical Tasks

- Provide understanding, tap resources (Jacobs \& Jaques, 1990)

- Boundary spanning, direction setting, operational management (Zaccaro, 1996)

- Transformation (Jablonsky, 2001)
Systems Level Individual Capability - Cognitive capacity (Lewis \& Jacobs, 1992)

- Cross-service relationships, problem solving, networking, consensus building (Lucas \& Markessini, 1993)

- Behavioral complexity (Hooijberg \& Quinn, 1992)

- Self-awareness, adaptability (U.S Army, 2001; Briscoe \& Hall, 1999)

Research Opportunities

- Transformation - matching organizational change to the changing nature of war

- Joint culture - moving from interservice rivalry to a joint profession

- Measuring effectiveness - leading a warfighting, peacekeeping, and humanitarian assistance force

Fig. 2. Systems level military leadership. 
political scientists, sociologists, and historians, an examination of this area brings up some interesting issues facing very senior military leaders. The debate has deep historical roots with one group siding with the Huntington (1957) view espoused in his classic, The Soldier and the State and the other group siding with the Janowitz (1960) perspective offered in his classic, The Professional Soldier. According to Huntington, a civil-military ideological gap exists between a generally conservative officer corps and a more liberal and individualistic society. This gap must be managed and tolerated by civilian society as it relies upon the military's expertise to defend the nation. Janowitz also identified a civil-military gap, but argued that the military must lessen the gap or the military will become less responsive to civilian control.

With the maturing of the all-volunteer military that replaced the conscript military in 1973, studies have recently emerged claiming that the civil-military gap has reached crisis proportions in two areas. First, some researchers believe that the military has grown increasingly isolated from the society it is tasked to protect. These concerns are based on the Janowitz view that the military culture should be representative of societal culture and result from claims that the military is, in addition to other aspects, becoming more conservative (Ricks, 1997), religious (Holsti, 2001), masculine (Morris, 1996), and Republican (Bacevich \& Kohn, 1997; Holsti, 1998) than society in general. In the words of former Secretary of the Navy, John Lehman, "We have created a separate military caste" (Lehman, 1994, p. 12). Those from the Huntington camp, while also viewing military culture as different from societal culture, either argue that the differences are either inconsequential or that the distinct military culture is more effective for the military's unique war-fighting mission (Hillen, 1999; Snider, 1999).

Some researchers have also voiced concern that the supposed estrangement of the military from society may eventually lead to military reluctance in obeying civilian authority. While the possibility of a U.S. military coup is out of the question (although see Dunlap, 1992, for an interesting essay about a fictional future revolt), some researchers point to what they view as near military insubordination in events such as the resistance to the lifting of the ban on homosexual behavior or too much military influence on defense policy in Bosnia (Kitfield, 1998; Kohn, 1994).

One dimension affecting the gap between society and the military is the often tenuous relationship between the media and the military. Despite a recent history of hostility between the two institutions (Ethiel, 2000), the military is currently coming down from the heights of a relationship of cordiality established during Operation Iraqi Freedom. The recent reinvigoration of the embedded media concept was both commended (e.g., Smolkin, 2003) and criticized (e.g., Burnett, 2003) for its role in public relations during combat. The current task for systems leaders is to now manage public relations during a time when the military's role shifts from major combat operations to peacekeeping (Moskos, 2000).

With rapid increases in real-time reporting (Seib, 2002), the military has only recently been forced to fully embrace the importance of managing public relations at the systems level. While most military leaders in the past were shielded from media exposure because of bureaucratic restrictions or physical inaccessibility, the military is now integrating public 
relations into all levels of its leadership education. For example, during a 2-week strategic crisis exercise at the U.S. Army War College, students (mostly colonels) are subjected to "interviews" by role-playing media representatives. The short notice interviews put a microphone in the students' faces with cameras rolling and hot klieg lights adding to the atmosphere.

Interestingly, while the relationship with the media has varied over the years, public trust in the military as an institution has increased steadily. In 1975 , only $20 \%$ of people ages 18-29 said they had a great deal of confidence in those who ran the military (Harris Poll, 2003). Compare that with a recent poll by the Harvard Institute of Politics (2002) that found that $70 \%$ of college undergraduates trust the military to do the right thing either all or most of the time. Thus, for the military as an institution and using a systems level perspective, public relations appear to have improved steadily over the past two decades.

Issues in civil-military relations present military leaders at the systems level unique challenges as they strive to determine and maintain the delicate balance between professional expertise, subordination to civilian authority, and representativeness of society. While it is true that CEOs are also held accountable by their boards of directors, police chiefs also struggle with subordination to city councils, and universities also strive to match the diversity of their surrounding society, military leaders must deal with the deeply engrained American belief that standing armed forces invariably become a tool of tyranny (Johnson \& Metz, 1995). Civil-military relations, to the systems level military leaders, are important simply because the consequences are so large.

Other aspects of the military's specific environment deserve attention because of the implications for senior military leaders. Just as most systems level leaders in other large organizations are exploring the use of outsourcing during a time of cost cutting (e.g., Masters, 2002), senior military leaders are also turning to private contractors to conduct the work of the military. In the case of the military, however, not only are ancillary, bureaucratic functions being outsourced, but core competencies are also being contracted out (Avant, 2002). For example, private U.S. military contractors occupy positions as cadre in over 200 Reserve Officer Training Corps (ROTC) departments, serve as recruiters in hometowns throughout the U.S., routinely train foreign armies, and are even assigned as bodyguards of the president of Afghanistan. Senior military leaders must grapple with issues of accountability, security, and control of contractors who may be on the battlefield or in the forefront of American foreign policy (Wayne, 2002). Contractors have always been a part of the military, but with the blurring of the distinction between the front line and rear areas, as well as outsourcing accession and leader development functions, senior military leaders are facing new leadership challenges.

With the recent deluge of corporate scandals hitting the headlines, ethics are again being discussed and studied with renewed vigor. For military leaders at the systems level, new issues in ethics are also being confronted, but in a much different way. American military leaders are accustomed to waging war guided by moral obligations based on Western values, allegiance to the Constitution, and adherence to the laws of war (Buckingham, 1995; Cook, 2000). With the attacks of September 11th and the global war on terrorism, the U.S. military 
now finds itself in a situation of ethical asymmetry - fighting an enemy that does not follow the same moral guidelines. Senior military leaders must strategically combat an enemy who deliberately targets civilians, uses suicide-attackers as a weapon, and exploits the freedoms inherent in American society to wage war (Cook, 2002). New ethical issues have emerged such as the raised expectations of minimal civilian casualties due to precision-guided weapons (Kahn, 2002), the role of assassination in the war against terrorism (Pape, 2002), the use of armed forces for humanitarian missions (de Torrente, 2001), and the encroachment of civil liberties in the quest for homeland security (e.g., Gould, 2002). In today's environment, senior military leaders are facing ethical dimensions not previously encountered in U.S. history.

\subsection{Critical tasks}

The critical tasks required of military systems level leaders include the functions noted in the extended multilevel leadership model as well as others described by researchers such as Mintzberg (1973) or Day and Lord (1988). T. Owen Jacobs heavily influenced the military research on systems level leaders in his role as the director of the Executive Development Research Group at the Army Research Institute. Jacobs used the Stratified Systems Theory or SST (Jaques, 1976, 1989) to examine tasks and capabilities across organizational levels in the military. According to Jacobs and Jaques (1990), two key tasks of senior military leaders are to provide a sense of understanding and purpose to the organization and to tap sources of resources. They carry out the former by reducing the uncertainty, ambiguity, and complexity presented by the organization's environment. They accomplish the latter by building consensus with those who hold the resources. According to SST, organizational critical task complexity increases by level of the organization. With increased levels of organizational critical task complexity, there must be a corresponding increase in leader cognitive complexity or capacity. Additionally, systems level leaders must also have longer time spans-their scope of vision of action over time.

Research conducted at the U.S. Army War College, an institution with the specific mission of educating strategic leaders, resulted in concluding that the primary critical task of strategic leaders is to create vision for organizations. Other key strategic tasks include shaping culture, managing relationships with other services (e.g., Navy or Air Force) or agencies, managing relationships with the national policymaking apparatus, representing the organization to society, and leading change within the military (Magee, 1998).

After reviewing the military and nonmilitary literature on executive leadership, Zaccaro (1996) developed an integrated model of executive leadership by incorporating aspects of conceptual complexity (Jacobs \& Jaques, 1990), behavioral complexity (e.g., Hooijberg \& Quinn, 1992), strategic decisionmaking (e.g., Bourgeois, 1985), and visionary leadership (Bass, 1985; House, 1977). Critical tasks for systems level leaders, according to Zaccaro, are boundary spanning, direction setting, and operational management.

One current critical task of systems level military leaders deserves more clarification than just dismissing it as providing vision or leading change. Senior U.S. military leaders are engaged in guiding the armed forces through transformation. Transformation refers to 
affecting fundamental changes in military capability including new doctrine, technology, concepts, and structure (Jablonsky, 2001). It is:

A process that shapes the changing nature of military competition and cooperation through new combinations of concepts, capabilities, people and organizations that exploit our nation's advantages and protect against our asymmetric vulnerabilities to sustain our strategic position, which helps underpin peace and stability in the world (U.S. Joint Forces Command, 2003).

As a result, the entire U.S. defense establishment is currently evaluating the way it does business to include the way it leads. Speaking at the U.S. Naval Academy in May 2001, President George W. Bush called for "a future force that is defined less by size and more by mobility and swiftness, one that is easier to deploy and sustain, one that relies more heavily on stealth, precision weaponry, and information technologies." He also advocated "fostering a military culture where intelligent risk-taking and forward thinking are rewarded, not dreaded," and "ensuring that visionary leaders who take risks are recognized and promoted" (Bush, 2001). Systems level military leaders are now attempting to transform a military that for decades was postured and trained to fight a Soviet invasion across Western Europe into a force capable of fighting the entire spectrum of war ranging from tank battles in the desert to humanitarian assistance in third world rural areas.

The recent Iraq War illustrated how transformation is being adopted as a systems level critical task instead of being considered as another passing fad. New technologies allowed special operations forces to roam across Iraq performing critical missions before official hostilities commenced. Unmanned aerial vehicles and hit-to-kill antimissile systems were used at unprecedented levels. The dash to Baghdad bypassed the conventional wisdom of massing overwhelming force before engaging the enemy (Gilmore, 2003).

Nevertheless, the radical change required with transformation is often subject to opposition. In an organization that is inherently resistant to change, transformation is not automatic. A potential case study for researchers in organizational change is the Chief of Staff of the Army's decision to switch the headgear of soldiers from hats to berets. The ensuing uproar was a foreshadowing of future resistance to other, more substantive, changes of the transformation. Another example of resistance to change was the continued support by Army system level leaders of the Crusader artillery system. Secretary of Defense Donald Rumsfeld eventually killed the US\$11 billion system and later replaced its biggest proponent, Army Secretary Thomas E. White. This incident raises another issue. While Kellerman and Webster (2001) review the literature on the American presidency, a particular area of potential research is the nature of military leadership conducted by civilians such as the Commander-in-Chief and the Secretary of Defense.

\subsection{Individual capability}

The individual capability of systems level leaders within the military has been the subject of a steady stream of research simply because the military must grow its own leaders. With no 
lateral entry into its most senior positions, the military must ensure that leader potential is identified and developed throughout the career of a leader.

As stated earlier, the most extensive and systematic research on systems level leaders was orchestrated by the Army Research Institute under the direction of T. Owen Jacobs. Using Strategic Systems Theory as the foundation, this research effort found that requisite knowledge and skills for senior military leaders included knowledge of national and international constituencies, consensus building, a systems perspective, and the ability to envision the future (Jaques et al., 1986; Harris \& Lucas, 1991; Jacobs \& Jaques, 1990).

Lewis and Jacobs (1992) took the cognitive complexity notion of SST and examined what they termed "cognitive capacity." They found that the potential for leadership at the systems level is a function of the capacity for creating an independent perspective of the strategic environment (Kegan, 1982) and thinking using abstract conceptual models (Jaques \& Clement, 1990). McGee, Jacobs, Kilcullan, and Barber (1999) analyzed samples from the senior military leaders and concluded that current personnel management practices in the Army do not consider leader cognitive complexity or conceptual capacity. They suggested identifying and developing strategic competence earlier in an officer's career as well as lengthening officer careers to allow longer utilization of strategic capacity.

Lucas \& Markessini (1993) interviewed 74 generals who reported requiring critical capabilities such as knowledge of cross-service relationships, an understanding of the military as an organization, problem solving skills, the ability to network, and consensus building skills. Markessini, Lucas, Chandler, and Jacobs (1994) interviewed senior executive defense civilians and found similar requisite skills and abilities in the civilian senior leaders.

The individual capabilities of systems level military leaders have also been analyzed through the lens of the behavioral complexity approach. Behavioral complexity suggests that effective leaders are not only cognitively complex, but are also able to perform a diverse set of roles and skills in the behavioral realm. It refers to the ability to play multiple, even competing roles, in a highly integrated and complementary way (Hooijberg \& Quinn, 1992). The predominant behavioral complexity model used to study senior military leaders has been Quinn's (1988) Competing Values Framework. Quinn develops eight major leadership roles based on two dimensions: flexibility versus control, and internal focus versus external organizational focus. The resulting roles are facilitator, mentor, innovator, broker, producer, director, coordinator, and monitor.

The competing values notion is especially useful in the military context that involves drastically differing situational requirements presented by both battlefield and garrison leadership (Hunt \& Phillips, 1991). A key notion of the battle/garrison competing values model is the balance between seemingly contradictory behavior roles. While some behaviors are effective in a garrison situation, the same behaviors are often inappropriate in a battlefield environment. Hooijberg, Bullis, and Hunt (1999) posit that the flexibility of acknowledging competing roles is especially valuable to systems level military leaders to create a mindset of continuous organizational transformation. This is critical as the military attempts transformation.

The military itself is fond of compiling long lists of required leadership knowledge, skills, abilities, and competencies. The U.S. Army War College, in its Strategic Leadership Primer 
(Magee, 1998), provides a list of nearly 30 strategic leader competencies that is extremely comprehensive and appears to capture every possible aspect of leadership ranging from inspiring others to critical self-examination. Similarly, in Field Manual 22-100, Army Leadership, the Army's doctrinal leadership manual, the skills and actions required of strategic leaders are a cumulative list of 41 competencies addressing the direct, organizational, and strategic levels. Twenty-one competencies are provided for the strategic level alone (U.S. Army, 1999b).

In the military's zeal to address all aspects of systems level leadership, the lists of strategic leader competencies are actually too comprehensive. At the individual level, it is difficult to assess one's leadership ability when the lists suggest that a strategic leader must be, know, and do just about everything. At the institutional level, the lack of parsimony makes it difficult to focus an institution's attention and resources on leader development when such a broad array of competencies is advocated.

In their review of strategic leadership, Boal and Hooijberg (2001) distill the essence of strategic leadership to three factors-effective strategic leaders must create and maintain absorptive capacity (Cohen \& Levinthal, 1990) and adaptive capacity (Black \& Boal, 1996) in addition to obtaining managerial wisdom (Malan \& Kriger, 1998). Absorptive capacity involves the ability to learn by recognizing new information, assimilating it, and applying it. Adaptive capacity involves the ability to change due to variations in conditions. Managerial wisdom consists of discernment and Kairos time (Bartunek \& Necochea, 2000). Boal and Hooijberg's assertion that absorptive and adaptive capacities are required at the systems level of leadership is very similar to recent Army leadership research. After an extensive review of current leadership practices and the implications of the ambiguous future environment of warfighting, the Army derived two metacompetencies: self-awareness and adaptability (Steele \& Walters, 2001; U.S. Army, 2001b). Based on work by Briscoe and Hall (1999), selfawareness and adaptability correspond closely to the concepts of absorptive and adaptive capacity. Although the Army metacompetencies are intended to apply to all levels of leadership, not just systems level leaders, it is interesting to see the parallel development of parsimonious leader capabilities in both the military and academic literature.

\subsection{Organizational culture}

The organizational culture of the military has recently been the subject of intense scrutiny. In the late 1990 s, the U.S. military was recovering from downsizing nearly $40 \%$ of its forces, severely reduced funding, and a host of new missions. With the pull of the New Economy and a push from growing discontent in the ranks, junior officers began to leave the military in droves. Organizational culture studies have resulted that examine the detrimental effects of the downsizing on survivors (McCormick, 1998; Wong \& McNally, 1994); the strain due to a rapid pace of operations, constrained resources, changing missions, shifts in demographics of the force, and leadership deficiencies (Dorn \& Graves, 2000; U.S. Army, 2001b); the generational gap between senior and junior officers (Wong, 2000); and the concern that the military has moved from being a profession to a bureaucracy (Snider \& Watkins, 2002). While the current organizational culture concerns are nowhere near the magnitude of those 
during the Vietnam War (e.g., U.S. Army, 1970), systems level military leaders continue to work towards aligning the military's organizational culture with organizational goals and purposes.

The military's culture has also been recently scrutinized concerning its tendency toward interservice rivalry (Beaumont, 1993; U.S. Government Accounting Office, 1993). Because each service focuses on its duties assigned by Congress (e.g., the Army focuses on land warfare, the Navy on maritime warfare), the services have tended to wage war with only minimal coordination with the other services. Thus, in Operation Desert Storm, the 43-day air war was followed by the 100-hour ground war-a sequential relationship between the Air Force and Army. In contrast, air support during Operation Iraqi Freedom was coordinated throughout the entire campaign with pilots communicating directly with soldiers on the ground. The trend towards warfare that does not rely solely, or even sequentially, on Army, Navy, or Air Force operations reflects a significant shift toward joint operations. This shift was greatly catalyzed by the 1986 passage of the Goldwater-Nichols Reform Act (Lewis, Brown, \& Roll, 2001; Lovelace, 1996) that sought to counterbalance the decision-making authority of the services by giving the joint commanders (e.g., General Franks of Central Command) a far greater voice in the determination of operational requirements. The push towards transformation discussed earlier has also added momentum toward jointness.

Recent indicators of the trend toward jointness include the emergence of joint doctrine, organizations (e.g., the Joint Staff), leader development (e.g., the Joint Forces Staff College), and a professional journal (e.g., Joint Forces Quarterly). Snider (2003) has even called for a separate "joint" profession in addition to the army, maritime, and aerospace professions. There has not been, however, a corresponding shift in leadership research exploring the implications of joint leadership at the strategic level (U.S. Government Accounting Office, 1993). As interservice rivalry gives way to jointness, leadership scholars may find research opportunities examining issues such as leading an organization with several distinct service cultures, maintaining a service identity while working in a joint environment, or the impact of the Joint Staff on civil-military relations.

Two particular studies are illustrative of context specific research conducted on the military's organizational culture. The first, resulting from two racially motivated murders, reported on the extent of extremism in the U.S. Army (U.S. Army, 1996). The report concluded that while there was minimal evidence of extremist activity in the Army, preventive training needed to be emphasized. The second focus examined the U.S. Army's organizational culture in the wake of the Aberdeen sexual harassment scandal (U.S. Army, 1997a). That study reported the results of nearly 30,000 soldier surveys and over 9,000 interviews. The study concluded that the Army's organizational culture was not conducive to engendering dignity and respect in the force. It bluntly stated, "Passive leadership has allowed sexual harassment to persist; active leadership can bring about change to eradicate it" (p. 2).

\subsection{Organizational effectiveness}

While wartime victory has routinely been the measure of military organizational effectiveness, the military has often struggled with measures of organizational effectiveness, or 
readiness, when not at war. Headlines in 1998 revealed the problem when the heads of the Army, Navy, and Air Force changed their Congressional testimony in just six months from being on the "razor's edge" of readiness to being in the depths of a readiness crisis. In addition to the unpredictability of the unstable global security environment, much of the difficulty in assessing the military's readiness stems from a reliance on the availability rather than the capability of systems as an indicator of readiness. Studies have explored the use of competing values (Phillips \& Wong, 1990) and goal attainment (U.S. Army, 2000) approaches, but the military continues to investigate how to best assess its effectiveness in an uncertain and changing world.

In an effort to include more than just the availability of systems as a measure of readiness and in response to the sexual harassment scandal that plagued the U.S. Army in 1996, the Army published the Human Dimensions of Combat Readiness (U.S. Army, 1997b). The study outlined 318 actions to improve the human relations environment to include an emphasis on Army values and heritage. Not surprisingly, the report begins with "Leadership is the key to preventing sexual harassment in the Army" (p. 1-1).

\section{Organizational leadership domain}

According to Hunt (1991), organizational leaders operate at the strategic business unit level with an organizational time span of 2 to 10 years. Instead of confronting the external environment as systems level leaders do, leaders at the organizational level emphasize the bounded open systems established higher up. Leaders at this level manage organizational processes and are concerned with things such as technology, structuring of subunits, and information and measurement systems. It is this domain that is the buffer between external environmental turbulence and the rational focus of the lower levels.

In the military, this level of leadership includes colonels to two-star generals with time in the military ranging from 22 years to 32 years. Two-star generals command divisions - units of about 16,000 to 20,000 soldiers that have all the necessary structure to be self-sustainable when deployed. Readers of military history will recall how the 1st Infantry Division stormed ashore at Omaha Beach or the 101st Airborne Division parachuted into Normandy. Today, divisions are still the main deployable unit (e.g., the 3rd Infantry Division led the recent coalition drive into Baghdad), but the realities of limited wars and the necessity for quicker responses to crises is driving the U.S. Army to make brigade-size elements-led by a colonel - the deployable unit. Brigades range from 3,000 to 5,000 people, although the new deployable brigades will be much larger.

Interestingly, as Fig. 3 graphically demonstrates, there is a relative paucity of military research done at this level. It may be that there is a degree of glamour studying either the direct or the systems level of military leadership. The former examines battlefield leadership while the latter deals with leaders responsible for vast amounts of people and weighty decisions. The organizational level is often overlooked as leaders at this level are usually removed from direct contact with the enemy and are not planning campaigns or strategic decisions for the military. Additionally, access to this level of leader is often hindered due to 


\begin{tabular}{|c|c|c|}
\hline $\begin{array}{l}\text { Orgn'l Level Critical Tasks } \\
\text { - Integrate technology (Cebrowski \& } \\
\text { Gartska, 1998; U.S. Department of } \\
\text { Defense, 2001) } \\
\text { - Restructure deployable units }\end{array}$ & $\begin{array}{l}\text { Orgn'l Level Individual Capability } \\
\text { Homogeneity of senior officers } \\
\text { (Gailbreath et al., 1997) } \\
\text { - Role diversity (Mumford, Zaccaro, et } \\
\text { al., 2000) } \\
\text { - Knowledge, problem-solving, systems, } \\
\text { and social skills (Mumford, Marks, et al., } \\
\text { 2000) } \\
\text { - Innovator (Rosen, 1991) }\end{array}$ & $\begin{array}{l}\text { Orgn'l Level Organizational Subculture } \\
\text { - Technology dependent subculture } \\
\text { (Shamir et al., 2000) }\end{array}$ \\
\hline
\end{tabular}

\begin{tabular}{|c|}
\hline Orgn'l Level Orgn'l Effectiveness \\
\hline $\begin{array}{l}\text { Research Opportunities } \\
\text { - Leading with technology - how much is too } \\
\text { much? } \\
\text { - Future leaders - developing innovation now } \\
\text { - Abandoning the phalanx - restructuring the } \\
\text { deployable Army }\end{array}$ \\
\hline
\end{tabular}

Fig. 3. Organizational level military leadership.

the relatively small population size of available commanders. Regardless, this level of leadership is fertile ground for leadership researchers-especially given the renewed emphasis on the brigade as a deployable unit.

\subsection{Critical tasks}

One of the key critical tasks of military organizational level leaders is integrating the recent quantum leaps in technology into organizational usage. The overarching technological theme in the U.S. military has been the move toward network-centric warfare (Cebrowski \& Garstka, 1998; U.S. Department of Defense, 2001). Just as the corporate world strives for information superiority in a market space, network-centric warfare is information superiority in a battle space. Network-centric warfare is achieved through sensing via unmanned aerial vehicles (UAV), unattended ground sensors, and increased reconnaissance-all networked together to develop a shared awareness.

An example of this is the Force XXI Battle Command Brigade and Below (FBCB2) system. FBCB2 is a vehicle-mounted system that provides situational awareness by collecting, integrating and displaying a common picture of the battlefield that is consistent in both time and space for each user. Using global positioning system technology, the geographical location of individual soldiers, vehicles, command posts, and facilities can be collectively displayed on a screen. Communications between users of FBCB2 are not restricted to the relatively short transmission distances of radios, but instead rely on emails via satellite (cf. Gegax, 2003). During the blinding sandstorm that blanketed units during Operation Iraqi Freedom, FBCB2-equipped units were able to continue navigating and communicating despite zero visibility conditions.

The implications of the major advances in technology are significant. Friendly-fire incidents are minimized as friendly and enemy forces are digitally identified. From an air force base in rural Virginia, remote-control pilots are able to direct U-2 reconnaissance 
aircraft and Predator UAVs to conduct real-time missions in Afghanistan. Soldiers on the ground can receive satellite imagery from the other side of the world within minutes.

Yet the increases in situational awareness also present significant leadership implicationsespecially for organizational level leaders who control the information flow to direct level leaders. Organizational level leaders must consider several possibly detrimental aspects of network-centric warfare. First, with higher level leaders able to see the situation at lower levels, there will be an increased potential to micromanage the situation instead of trusting the judgment of their subordinate leaders (Bunker, 1998). Second, leaders may be overloaded with data and unable to discern what is important (Jantzen, 2001). Finally, leaders may rely excessively on sensors and lose the necessary intuition for battle command (Holland, 2003; Murray, 2002). Military leaders at the organizational level have the task of both exploiting and limiting the effects of technology on the organization.

Military leaders at this level are also confronting the need to restructure military organizations based on the changing world situation. With the advent of the all-volunteer force and the increased role of the military in the post-Cold War world, retention emerged as a critical issue. Continual, unforeseen deployments were resulting in uncertainty for members of the military and their families. While being away from home was a known factor for those who volunteered for the military lifestyle, the repetitive, no-notice, and often open-ended deployments began to take a toll on families. The Air Force responded by creating 10 matrix organizations and rotated deployment responsibility through each of these Air Expeditionary Forces. The Army is now contemplating a similar restructuring in an attempt to bring predictability to the force (Shanker, 2003). The leadership implications for these changes in restructuring have not been fully explored and present opportunities for leadership researchers.

\subsection{Individual capability}

Turning to the individual capabilities of organizational leaders, several studies have examined leader predispositions and skills at the organizational level. The attractionselection-attrition model (Schneider, 1987; Schneider, Goldstein, \& Smith, 1995) suggests that organizations attract, hire and retain people with similar characteristics such as personality, values, and attitudes. With the military relying on an internal promotion system, leaders are developed from within-lateral transfers into the organization are not possible. Therefore, one would expect a great deal of homogeneity among military leaders. Gailbreath, Wagner, Moffett, and Hein (1997) administered the Myers-Briggs Type Indicator (Myers \& McCaulley, 1985) to two samples of organizational level Army officers and found that the senior leaders had very similar behavioral preferences. Leaders with sensing-thinkingjudging preferences were more common than those with a feeling preference.

Mumford, Marks, Connelly, Zaccaro, and Reiter-Palmon (2000) identified types of individuals entering the Army based on ability, personality, and motivational characteristics. After identifying seven types at the direct level of leadership, they turned to the organizational level and found that three of these types are particularly prominent in senior officers. The three types - motivated communicators, social adaptors, and thoughtful innovators- 
reinforce the stereotypical view that successful military leaders are extroverted and achievement oriented, but also show evidence that senior leaders can be introverted and intellectually oriented. They conclude that, contrary to the homogeneity model (Schneider et al., 1995), a role diversity model (e.g., Quinn, 1988) is more appropriate at the organizational level. In a related study, Mumford, Zaccaro, et al. (2000) used a crosssectional design to assess leadership skills across the levels of leadership in the Army. They found that increased levels of knowledge, problem-solving skills, systems skills, and social skills were found at the organizational level. Because more senior leadership positions require higher levels of skill in general, they propose that leader development strategies must be carefully tailored.

The shift to more deployable, agile units in the future will require leaders with different capabilities and recent military thinking has reflected that need. Changing from plan- to intent-centric operations and from static command posts to command and control on the move (U.S. Army, 2001c) will require innovative and creative leaders-especially at the organizational level where deploying units will be operating much more independently than in the past (Isaacson, Layne, \& Arquilla, 1999). Rosen (1991) points out that a culture of innovation to create these leaders must come from within the military. It cannot rely on "mavericks" who buck the system. Mavericks may have innovative ideas, but they reject the system and, in turn, they are rejected by the system. In an institution where promotion paths are well defined, mavericks will never gain the power to change the whole military. Likewise, Rosen notes that a culture of innovation cannot be forced on the military by civilian appointees. Civilians are outsiders who wield power, but unless the uniformed military accepts the need for change, civilians cannot make the officer corps view innovators as legitimate. Rosen posits that military innovation occurs when senior military officers formulate a strategy for innovation that protects leaders who show innovation.

\subsection{Organizational subculture}

Shamir, Goldberg-weill, Breinin, Zakay, and Popper (2000) conducted an interesting study that points to the influence of technology on military organizational subcultures. Comparing 24 infantry companies with 21 tank companies in the Israeli Defense Forces, they hypothesized that the more technology-dependent and mechanistic subculture of armor units would lead to differences in leadership style in the two types of units. They found that infantry leaders were more open toward their subordinates, de-emphasized social distance, and relied more upon a supportive leadership style. The armor leaders used a more formal leadership style and emphasized planning, order, rules, and regulations.

The Shamir study highlights a phenomenon that has gradually become apparent in the military - the influence of technology on subcultures and consequently leadership styles, development, and selection. Consider two military leaders. One goes to flight school and eventually pilots a Predator UAV in Afghanistan from a thousand miles away. The other joins the special operations forces and eventually leads a 12-man team linking up with indigenous forces to include riding into battle on horseback. The differences in the organizational subcultures are enormous, yet both leaders are selected, developed, and promoted by the same 
system. Obviously, future research is warranted on the implications of the impact of technology on military leaders.

\section{Direct leadership domain}

Direct leadership is the most widely studied of the three leadership domains in the military most likely because it provides access to the largest number of leaders (Fig. 4 summarizes the direct level military literature). Hunt (1991) states that direct level leaders operate in a bounded subsystem where the processes are direct and concrete. Defining tasks, setting goals, and monitoring progress are key requirements at this level. In contrast to long time horizons at higher levels of leadership, the span of discretion ranges from the immediate to 2 years at the direct level.

In the military, direct level leadership occurs predominantly at the battalion level and below. Battalion commanders are lieutenant colonels who command units of up to 500 soldiers and have been in the military for about 16 years. Company commanders are captains who have been in the military for approximately 6 years, and Sergeants Major and First Sergeants are noncommissioned officers (NCOs) who have been in the military for

External Environment

- Training/garrison, deployment/combat, schooling/evaluation contexts (Hodges, 1994)

\begin{tabular}{|c|c|c|}
\hline $\begin{array}{l}\text { Direct Level Critical Tasks } \\
\text { - Task overload (Wong, 2001) } \\
\text { - Officer and NCO roles (Chen \& } \\
\text { Bliese, 2002) }\end{array}$ & $\begin{array}{l}\text { Direct Level Individual Capability } \\
\text { - Agreeableness and conscientiousness } \\
\text { (Bartone, et al., 2002) } \\
\text { - Dominance, energy level, and internal } \\
\text { control (Bradley et al., 2002) } \\
\text { - Conscientiousness and extroversion (Judge } \\
\text { et al., 2002) } \\
\text { - Extroversion (Thomas et al., 2001; } \\
\text { McCormack \& Mellor, 2002) } \\
\text { - Demographic similarity (Vecchio \& Bullis, } \\
\text { 2001) } \\
\text { - Gender (Biernat et al., 1998; Rice et al., } \\
\text { 1984; Steinberg \& Foley, 1999) } \\
\text { - Motivation to lead (Chan \& Drasgow, 2001) } \\
\text { - Practical intelligence (Hedlund et al., in } \\
\text { press) } \\
\text { - Transformational leadership (Dvir et al., } \\
\text { 2002; Bass et al., 2003) } \\
\text { - Adaptability (Ployhart et al., 2002) }\end{array}$ & $\begin{array}{l}\text { Direct Level Organizational Subculture } \\
\text { - Subordinate perceptions (Shamir et al., } \\
\text { 1998) } \\
\text { - Existence of leadership climates } \\
\text { (Bliese, 2000; Bliese et al., 1994; Bliese \& } \\
\text { Halverson, 1996) } \\
\text { - Well-being (Bliese \& Britt, 2001) }\end{array}$ \\
\hline
\end{tabular}

Direct Level Orgn'l Effectiveness

- After action reports (Sullivan \& Harper, 1996)

Research Opportunities

- Leading in war and peace - critical tasks and

capabilities for combat and peacekeeping

- Nintendo leadership - effects of technology on

leading from a distance

- Effectiveness - including the human dimension

Fig. 4. Direct level military leadership. 
approximately 15 to 20 years. While NCOs certainly play an important role in higher leadership levels, their influence is primarily exercised at the direct level of leadership; consequently, this is the first level where we consider NCO leadership. Company-level leaders are responsible for between 50 and 200 soldiers.

It is important to consider the number of soldiers that direct leaders command, because the large numbers show that opportunities to study face-to-face leadership may be limited. Thus, it is not uncommon for studies of leadership at this level to use some form of aggregate follower variable in the research. For instance, studies may use unit aggregate ratings of performance as ways of studying leader effectiveness (e.g., Dvir, Eden, Avolio, \& Shamir, 2002) or they may aggregate subordinates ratings of leaders to study leadership climate (Bliese \& Castro, 2000; Chen \& Bliese, 2002). The usefulness of examining leadership climates will be discussed later in this article.

\subsection{External environment}

Although Hunt's (1991) model does not directly consider the impact of the external environment on direct leaders, we believe that it is important to consider the external environment by differentiating among three contexts where leadership research is conducted-(1) training/garrison context, (2) deployment/combat context and (3) schooling/ evaluation context. Each of these contexts carries different implications for the critical tasks, individual capabilities, organizational culture and mission effectiveness aspects of leadership research.

Military leadership research is often conducted in schooling/evaluation contexts. This setting provides a fairly high degree of control for both the researcher conducting the study and for the leader who is participating in the study. It almost goes without saying that leaders know what they will be doing and how their performance will be evaluated in the schooling/ evaluation contexts. Leadership research in schooling/evaluation contexts is valuable because it provides excellent experimental control, and it often has embedded performance measures. Nonetheless, the critical tasks and the individual capabilities associated with successful leadership performance in schooling/evaluation settings almost certainly differ in important ways from the critical tasks and individual capabilities associated with leadership in garrison and combat settings. For instance, personality traits such as extroversion may be positively related to performance in schooling and evaluation settings because they help individuals "stand-out" relative to their peers (Thomas, Dickson, \& Bliese, 2001), but may be negatively related to leadership performance in actual task settings (McCormack \& Mellor, 2002). Thus, while we review direct leadership studies conducted in schooling/evaluation settings; we take care to clearly identify these studies as a way of noting concerns about the generalizability of the findings to training/garrison and deployment/combat contexts.

Training/garrison contexts are also popular places to conduct military leadership research. The situation is less controlled than in the evaluation context; however, it is fairly predictable to plan such research because events that occur at the direct level of leadership are largely driven by a 6-month training calendar. The training calendar is a necessity designed to coordinate major activities among company and battalion sized units as they train to achieve 
higher level mission training objectives. For instance, limited numbers of gunnery and other ranges at a base or post make training calendars a necessity.

Training environments such as the National Training Center (a training area the size of Rhode Island with subject matter experts continually observing leaders and sensors continually tracking vehicles during simulated battles with a resident opposing force) would appear to be ideal venues to study the effects of direct leadership because they presumably provide unit performance metrics. That is, one could presumably examine the impact of direct leadership on platoon-level, company-level or battalion-level performance. The reality, however, is that it is very difficult to obtain reliable performance metrics at either the individual or unit level in major training exercise venues. Hodges (1994) provides a number of technical reasons why performance metrics are difficult to obtain, but certainly one major cultural reason is the military's belief that training exercises are meant to be developmental rather than evaluative in nature - thereby resulting in a culture that is hesitant to measure performance in a systematic way that would allow reliable comparisons across units. Thus, training/garrison based leadership studies often have difficulty obtaining reliable performance metrics even though the predictability of the context makes it fairly easy to obtain various forms of leadership data.

The context where the least amount of leadership research has been conducted is deployment/combat mission contexts. These environments are very unpredictable for both leaders and researchers, and access to units conducting deployment and combat missions is very limited, particularly in the early stages of engagement (e.g., Wong, Kolditz, Millen, \& Potter, 2003).

While combat and garrison are certainly different contexts, we argue that there is considerable similarity in the critical tasks and individual capabilities between the two settings. We take the position that specific critical tasks and individual capabilities may be more or less important depending upon the context. For instance, leader adaptability (as an individual capability) may be more important in combat than in garrison; however, adaptability is presumably important in both contexts. In contrast, as noted previously we maintain the critical tasks and individual capabilities of leadership in schooling/evaluation contexts are likely to be fundamentally different than those in garrison and combat.

\subsection{Critical tasks}

According to Hunt (1991), the critical tasks for direct level leaders center on two elements. First, direct leaders are responsible for executing orders (i.e., operating procedures) from higher elements that contribute to achieving the goals and missions of the larger organization. Direct leadership is the level where individual soldiers and small units carry out very specific tasks in support of higher level objectives. Second, direct leaders are responsible for developing and maintaining soldier skills and caring for the upkeep of equipment. Imbedded in this latter element is the notion that direct leaders are responsible for all aspects of soldier well-being.

Breaking critical tasks into the two dimensions of executing orders and maintaining the unit provide insight into some of the differences between training/garrison contexts and 
deployment/combat contexts. In deployment/combat contexts, the priority is on effectively executing orders to achieve mission objectives. The loss of personnel and equipment may be considered an unfortunate, though acceptable, aspect of mission success. In contrast, in garrison/training settings the emphasis is on maintaining or improving soldier skills and ensuring that equipment is mission ready; consequently, there is more latitude in terms of whether the unit does or does not achieve specific missions. That is, leaders in garrison/ training contexts would be expected to fail in a mission objective rather than sustain an injury or casualty. In contrast, the situation would be reversed in many combat scenarios. This does not imply that leaders in combat scenarios do not care about casualties in their unit, but that loss of life is part of warfare.

The tasks associated with executing orders and achieving higher level goals are certainly demanding. In fact, Wong (2001) has argued that these tasks are so demanding that direct leaders have few opportunities to exercise their own initiative. Nonetheless, it is critical to understand that the tasks associated with maintaining soldier well-being are an equally demanding aspect of the direct leadership role. At the company-level, in particular, direct leaders are responsible for every aspect of their soldiers' lives to include military schooling, finances, physical fitness, legal issues, and family concerns. Traditionally, the tasks associated with maintaining soldier well-being are considered the primary domain of the noncommissioned officers and a secondary domain for commissioned officers. Commissioned officers, in contrast, are expected to work more on tasks associated with executing higher level orders and providing role-clarifying direction.

Chen and Bliese (2002) studied differential leader roles in a garrison training environment and examined how NCO versus officer leadership contributed to soldier self-efficacy (soldiers' beliefs that they were capable of performing their jobs), and unit collective efficacy (the average rating of unit members' perceptions of unit readiness). In an examination of survey responses from 2585 soldiers in 86 companies, they found that NCO leadership climate operationalized as unit members' average perception of the competence and consideration of unit NCOs contributed to self-efficacy via psychological strain. In other words, units with high ratings of NCO leadership had soldiers with low psychological strain (i.e., enhanced well-being) and these soldiers also reported higher levels of job-related efficacy. Average ratings of officer competence and consideration also played a role in selfefficacy, but through another mechanism - namely, role clarity. Units with high ratings of officer leadership had soldiers who reported high role clarity (they knew what tasks and missions they needed to achieve), and this was a direct mediator of self-efficacy. Thus, both types of direct leadership contributed to soldier job-related efficacy but through two different elements of the critical tasks of direct leaders (maintain soldiers and execute missions) identified by Hunt (1991). We should note that Chen and Bliese (2002) also found that collective efficacy (the group's overall belief in their ability to perform their mission) was apparently driven more by ratings of officer climate than NCO climate-again supporting the notion that officers are primarily responsible for mission-oriented tasks.

From a path-goal perspective (House, 1996) one might expect the value that soldiers place on "directive path-goal clarifying leader behavior" versus "supportive leader behavior" to vary as a function of garrison versus combat environments. Path-goal theory, in fact, would 
predict that soldiers in combat settings would be particularly receptive to directive path-goal leader behavior clarifying policies, rules of engagement and procedures. It seems plausible, therefore, that officer leadership behavior may become increasingly important in combat situations. Likewise, path-goal theory suggests that leader supportive behaviors such as creating a friendly and supportive work environment are likely to be salient in garrison settings. Thus, one might expect NCO leadership climate to be more predictive than officer leadership climate of outcomes such as satisfaction and well-being in garrison settings.

While the critical tasks of direct leaders center on (a) mission execution and (b) maintenance of soldier morale and well-being, the relative importance of these two critical tasks varies by context. Clearly one of the ways schooling/evaluation contexts differ from garrison and combat settings is that the critical tasks in schooling/evaluation contexts are much more likely to be individually focused. That is, participants in schooling and evaluation contexts will focus on their own individual performance; they will rarely be responsible for the well-being of subordinates. In contrast, leadership in garrison and combat settings is much more collectively focused-leaders are judged largely on the performance of their units.

While the critical tasks of direct leaders has not changed appreciably with the end of the Cold War, it is important to note that advances in technology now allow direct level leaders with time spans as short as 3 months to make decisions that have systems level implications. For example, a company commander defending the Brcko bridge in Bosnia in 1997 wisely chose to defuse the situation through discipline and restraint despite being bombarded by a Serb mob with bricks, railroad ties, and Molotov cocktails. Had that incident escalated and been reported through the world media by the many reporters present, the entire Dayton Accords may have unraveled. The company commander's actions were based on a very limited time span, yet they had strategic implications for the entire Balkan region that would last for years. In addition to the shift away from massed armies where a direct level leader was merely a cog in a wheel, the increased visibility enabled by technology of all leadership levels has drastically increased the impact of direct level leader actions.

\subsection{Individual capability}

Given that many leadership researchers have backgrounds in psychology or other individual-oriented disciplines, it is perhaps not surprising that a great deal of research has been focused towards understanding individual capabilities of leaders. The goal of research of this nature is to identify attributes of the individual that predict effective leadership with an eye towards designing leadership development programs to enhance leadership. In this section, we consider recent military research as it relates to four facets of individual capability: (a) personality, predispositions and preferences; (b) gender and other demographics; (c) cognitive complexity; and (d) leadership skills.

\subsubsection{Personality, predispositions and preferences}

In the military, as in leadership research in general, research on leader background predispositions and preferences is mixed. Research on leader personality in the military, in 
particular, is fairly inconclusive and part of this problem is undoubtedly due to the fact that researchers have looked at a multitude of different personality characteristics thereby making any integration difficult (Chemers, 2000; Judge, Bono, Ilies \& Gerhardt, 2002). For instance, Bradley, Nicol, and Charbonneau (2002) conducted a longitudinal analysis of Canadian officers and found that officers who rated themselves highly in terms of dominance, energy level and internal control were rated as being more effective 3 years into their careers. In contrast, Bartone, Snook, and Tremble (2002) found that agreeableness and conscientiousness were related to ratings of leadership effectiveness in a longitudinal study of West Point cadets. It is relatively hard, however, to integrate the Bradley et al. findings with the Bartone et al. findings to provide an overall evaluation of the role of personality in military leadership because of the lack of overlap of personality characteristics in the two studies.

One promising solution to integrating the research on personality and military leadership is to collapse personality characteristics into a manageable number of subsets as was done by Judge, Bono, Ilies, and Gerhardt (2002). Judge et al. conducted a meta-analysis by categorizing previous personality leadership research into one of five categories corresponding to the big five personality trait it most closely resembled (extroversion, openness to change, agreeableness, conscientiousness, and neuroticism). The studies comprising the metaanalysis were further identified in terms of whether the study came from a government or military population (to include students in military service academies).

The meta-analysis revealed that neuroticism was negatively related to leadership effectiveness; while conscientiousness and extraversion were positively related. While these results suggest certain personality traits are related to military leadership, we should caution that even these results are difficult to interpret because they include nonmilitary samples in the form of other government agencies in addition to studies from schooling/evaluation settings. Recall, that we consider leadership research conducted in these contexts to be different from research conducted in actual garrison or combat settings. In addition, we believe that various personality traits may become more or less important depending upon whether the leader is operating in a combat or garrison setting. Consider, for instance, that Thomas et al., (2001) found extroversion to be positively related to performance ratings in an assessment center setting. In contrast, McCormack and Mellor (2002) found extraversion to be negatively related to leadership ratings in studies of Australian officers in the actual job situation. Thus, we still consider the question of whether or not there are any personality traits consistently related to leadership effectiveness to be unresolved, and perhaps unresolvable in any absolute sense - there may simply be too many contingencies to make absolute statements about the importance of personality.

Before concluding our discussion of personality, it is worth noting some interesting research on individual background predispositions and preferences related to personality conducted by Chan and Drasgow (2001). Chan and Drasgow conducted a study in schooling/ evaluation settings to determine whether one can quantify a construct of "motivation to lead," and examine whether motivation to lead has any predictive power when it comes to understanding the importance of personality and other individual differences in direct leadership situations. Chan and Drasgow argued that to understand the link between individual background and leadership, one must also consider an individual's motivation to 
lead as a key mediating variable - factors such as conscientiousness, which one expects to be related to leadership may not, in fact, be related if the individual has no motivation to lead. Studies of recruits in the Singapore military showed that motivation to lead added incremental power when predicting ratings of leadership effectiveness. The construct of "motivation to lead" seems as though it could help shed light on the link between personality and leadership in combat, training and garrison settings, and we look forward to future research on this topic.

\subsubsection{Gender and other demographics}

A specific background factor that has drawn particular attention from leadership researchers is gender. About $15 \%$ of the officer and enlisted ranks in the U.S. military are women (U.S. Department of Defense, 2000). Despite a plethora of studies examining the acceptance of women in the military (e.g., Armor, 1996; Durning, 1978; Pershing, 2001; Rosen, Fancher, \& Knudson, 2003), there have been very few studies examining the role of gender and military leadership. As the novelty of women in the military wears off, it would be expected that researchers would shift to more substantive gender issues other than just integration.

Of the studies examining gender and leadership, several addressed gender stereotyping. Biernat, Crandall, Young, Kobrynowicz, \& Halpin (1998) studied direct level U.S. Army officers using the shifting standards model (Biernat, Manis, \& Nelson, 1991) as it applies to sex-based stereotyping and found that stereotyping generally increased over time and promale judgment bias was more evident in rankings than in ratings. Interestingly, they did not find strong support for a differential standard use on the basis of race that they attribute to the Army's explicit prohibition on race-based standard shifts. Rice, Instone, and Adams (1984) studied West Point cadets to determine if the relationship between leadership process and leader success was different for male and female leaders. They found no support for sex-role stereotypes. They did point out, however, that their sample focused on the first West Point class with women and therefore there was an explicit strong endorsement of gender equality from the Army and the Military Academy. In a similar study, Steinberg and Foley (1999) conducted surveys and interviews in the U.S. Army to determine if white men were less likely to mentor women. They found no gender differences in whether the women were mentored, in the type of assistance they received, and in the helpfulness of those mentoring behaviors.

An interesting twist on the idea of looking at gender and other demographic characteristics in the absolute sense has been to examine demographic similarity between subordinates and supervisors as a predictor of organizational outcomes. Vecchio and Bullis (2001), for instance, examined demographic similarity (gender, race, and ethnicity) in 2883 subordinate-leader dyads in the military. The dyadic pairs were selected by surveying leaders (officers, warrant officers and NCOs) about their dyadic relationships with their supervisors. In the study, they found that all forms of demographic similarity were weakly associated with satisfaction with one's supervisor and continued membership in the military. They also found that satisfaction with one's supervisor tended to drop as a function of time spent together-a trend that was particularly salient in female-female dyadic pairs and in minority-minority dyadic pairs. Finally, they found a weak trend suggesting that female supervisors tended to receive somewhat less favorable assessments than did male supervisors. All in all, these results suggest that demographic variables play, at most, a weak role in terms of leadership 
effectiveness. Based on the Vecchio and Bullis (2001) data, one might reasonably conclude that demographic similarity between leaders and subordinates plays as significant a role in leadership effectiveness as do demographic variables in any absolute sense.

\subsubsection{Cognitive complexity}

Another individual capability considered in Hunt's (1991) model is cognitive complexity and social cognition. Certainly, there are both theoretical and empirical reasons to believe that social skills and knowledge are important contributing factors in direct level leadership effectiveness (Lord \& Hall, 1992; Zaccaro, Gilbert, Thor, \& Mumford, 1991). In recent years, this has been an active area of military research. One of the basic premises of this work has been the idea that the link between individual difference factors such as cognitive ability and outcomes such as performance is mediated by (a) problem solving skills, (b) social judgment skills, and (c) knowledge (see Connelly, Gilbert, Zaccaro, Marks \& Mumford, 2000). Along similar lines, more recent work has examined the link between practical intelligence and leadership (Hedlund et al., 2003). Hedlund et al., used interviews with U.S. Army officers to develop the "Tacit Knowledge for Military Leaders" inventory. This inventory was given to over 500 direct leaders in garrison settings (platoon leaders, company commanders and battalion commanders) to assess the leaders' tacit knowledge of military leadership. The direct leaders' ratings on the inventory were found to be related to ratings of effectiveness from peers or supervisors. This work is important because it expands our understanding of how we conceptualize intelligence. Presumably, some individuals will be better able to acquire tacit knowledge than will others, and this ability may be predictive of leadership success.

\subsubsection{Leadership skills}

Leadership skills are the final component of the individual capability of direct leadership we consider. The current dominant paradigm for leadership skills is transformational based theories (Chemers, 2000). One would expect that the transformational leadership findings conducted in nonmilitary settings would generalize to military settings, and this appears to be the case. Dvir et al. (2002) have recently conducted a fascinating study on transformational leadership in the Israeli army. The work by Dvir et al. is rare because it utilized a randomized experimental design where transformational leadership skills were taught to one set of direct leaders while other leaders received regular leadership skill training. Dvir et al. evaluated how leadership skill training in transformational leadership impacted subordinates. Results revealed that direct subordinates of leaders who were provided transformational leadership skills were operating at more of their full potential (i.e., were more developed) than were direct subordinates of leaders provided regular training. In addition, indirect subordinates of the direct leaders (unit members) performed better if their leaders had received transformational leadership training than if they had not. The research by Dvir et al. is critical for it clearly demonstrates a causal link between transformational leadership and performance.

In another study of transformational leadership, Bass, Avolio, Jung, and Berson (2003) examined the use of transformational and transactional leadership ratings collected in stable conditions in predicting unit performance in more stressful conditions. Bass et al. measured 
leadership in 72 light infantry platoons two weeks before a training exercise and then examined the relationship with platoon performance. They found that both transformational and transactional contingent reward leadership ratings of platoon leaders and sergeants positively predicted unit performance.

A final direct leadership skill of interest to the military is adaptability. The logic for why adaptability is considered important is clear-in the current military environment direct leaders are expected to seamlessly transition between training/garrison settings and combat/ deployment settings. This transition undoubtedly requires highly adaptable leaders. While the concept of adaptability is clear, the operationalization of the term is murky. Recently, Ployhart, Satlz, Mayer, and Bliese (unpublished data) have developed a 40 item instrument designed to assess eight dimensions of individual adaptability. These eight dimensions are based upon the eight dimensions of adaptability performance identified by Pulakos, Arad, Donovan, and Plamondon (2000).

In the Ployhart et al. (in preparation) scale, respondents are asked to rate themselves in terms of their perceived (1) ability to handle crisis, (2) ability to handle work stress, (3) ability to solve problems creatively, (4) ability to deal with unpredictability, (5) ability to learn new skills, (6) interpersonal adaptability, (7) cultural adaptability, and (8) physical adaptability. Preliminary work conducted using Reserve Officer Training Corps (ROTC) advanced leadership camp cadets indicates that self-ratings of adaptability are related to subsequent leader performance ratings (Ployhart et al., in preparation). Future work needs to establish the discriminant validity of these measures as being distinct from big five measures. In addition, work needs to be done in garrison and combat settings, and finally research needs to determine whether adaptability skills can be taught as a way of enhancing leadership effectiveness.

\subsection{Subcultures and subclimates}

Integral to many studies of military leadership is the notion that leaders develop work climates and that these climates can be differentiated using responses from subordinates (e.g., Shamir et al., 1998). Recall that the large group sizes at the direct level of leadership make face-to-face interactions between subordinates and direct leaders such as battalion commanders, company commanders and first sergeants relatively rare. To act upon the notion that shared leadership climates exist from either a pragmatic or a purely research perspective, it is important to empirically demonstrate the existence of "climates." Not surprisingly, therefore, there has been considerable interest in finding ways to empirically demonstrate the existence of leadership climates and to show that these climates are related to important outcomes.

Research establishing the empirical existence of leadership climates has tended to be largely methodological. The goal of this research is to demonstrate that individuals in the same group (i.e., a U.S. Army company) show more similarity in leadership ratings than would be expected by chance. Bliese (2000) reviews a number of tests of similarity effects including estimating intraclass correlation coefficients (ICCs); $r_{w g}$ values (James, Demaree \& Wolf, 1984; James, Demaree \& Wolf, 1993) and random group resampling estimates—RGR 
(Bliese, Halverson, \& Rothberg, 1994). Each of these indices provide a somewhat different representation of the patterns of responses among group members. What is important about these indices, however, is that when they are applied to leadership ratings the indices repeatedly provide convincing evidence of the existence of leadership climates-group members even of large Army companies do develop a shared sense of social reality about their leadership. For instance, Bliese and Halverson (1996) contrasted ratings of within-group similarity among company members on the four separate dimensions of work hours, leadership, cohesion and well-being, and showed that ratings of leadership showed the second most pronounced evidence of shared climate in ICC tests, and the first most pronounced evidence of climate in RGR tests. The ICC tests suggested that group membership accounted for an impressive $16 \%$ of the variance in individuals' reports of leadership. As another example, in studies of soldiers deployed to Haiti in 1994 as part of Operation Restore Democracy, the ICC(1) value for ratings of leadership was .09 indicating that about $9 \%$ of the variance in any one respondents leadership rating could be explained by group membership (Bliese, Halverson, \& Schriesheim, 2002).

One interesting area of research on climates and subclimates in military climate research has been work looking at units that fail to show agreement about leadership. From a social influence perspective, well-functioning groups should agree about matters of importance to the group (Festinger, 1954). Consequently, a failure to agree about unit leadership may be indicative of a poorly functioning team. Bliese and Halverson (1998) and Bliese and Britt (2001) both provide evidence showing that poor agreement about leadership is related to low well-being among group members. Presumably, poor agreement about leadership would be related to poor ratings on group process variables such as communication and to unit outcomes as well. Work of this nature remains to be done.

\subsection{Mission effectiveness}

The concept of mission effectiveness, like many of the other dimensions we have discussed, will vary depending upon whether the environment is training/garrison or an actual mission deployment. In the deployed environment, the definition of mission effectiveness will be tied to specific mission objectives. Interestingly, mission effectiveness may be more difficult to assess in training/garrison environments than in deployed environments. Officially, direct leaders in the Army have their effectiveness evaluated via monthly Unit Status Reports (USR) and Quarterly Training Briefs (QTBs). The USR is tailored to particular types of units, but covers areas such as the percentage of soldiers completing weapons training, the percentage who have completed Nuclear, Biological and Chemical training, etc. QTBs are briefings given to the next higher unit on training issues, such as the status of Mission Essential Task List items. For example, company commanders in tank battalions report the number of tank crews that have successfully qualified with their tank on a range, an item that directly impacts combat effectiveness. Presumably effective leaders will have units that score highly on these objective measures.

One problem with relying solely on the USR or QTB, however, is the very real possibility that unit effectiveness in deployed situations will depend at least somewhat to variables not 
assessed in the USR or reported during the QTB. Unit member task cohesion, for instance, is likely to impact unit effectiveness in deployed settings, but is not routinely assessed in the USR process. One important area for future research is to examine the link between direct leadership and more broadly conceptualized definitions of unit effectiveness. Campbell (1999), for instance, provides an excellent starting point by conceptualizing performance in terms of the eight dimensions of (1) job specific task proficiency, (2) nonjob specific task proficiency, (3) written and oral communication proficiency, (4) demonstration of effort, (5) maintenance of personal discipline, (6) facilitation of peer and team performance, (7) supervision/leadership, and (8) management/administration. A promising research area may be to adapt Campbell's individual performance dimensions to unit-level equivalents and determine how direct leadership relates to these dimensions.

Interestingly, one aspect of unit effectiveness that originated in the military and migrated to the corporate world is the use of the After Action Report or AAR (Sullivan \& Harper, 1996; U.S. Army, 1990b). The AAR is a brutally honest self-assessment conducted after an event where soldiers focus on performance standards and review what happened, what strengths should be sustained, and what weaknesses can be improved. Outside observers are often shocked at the organizational climate that allows the lowest ranking privates to candidly give their perspectives that sometimes differ from the views of their leaders. At the tactical level, such self-examination leads to better procedures and performance. At the strategic level, "the AAR has ingrained a respect for organizational learning, fostering an expectation that decisions and consequent actions will be reviewed in a way that will benefit both the participants and the organization, no matter how painful it may be at the time." (Sullivan \& Harper, 1996, 193)

\section{Conclusion}

We have attempted to describe the many facets of military leadership using Hunt's (1991) extended multilevel leadership model. We summarized research at the systems, organizational, and direct levels and addressed leader critical tasks and individual capabilities at each level. We also addressed the external environment confronting the military as well as the organizational culture within the armed forces. Our original goal in writing this article, however, was to identify some of the key research needs in military leadership.

The military will always be fertile ground for context-free leadership researchers-leaders abound and military members view both quantitative and qualitative assessments as routine. In this article, we focused more on the context-specific research and thus our suggestions for future research also tend to be context-specific. In addition to the research opportunities described in the article and noted in the figures, the following suggestions provide some specific thoughts on where we think leadership researchers might be most productive in the military context.

1. Transformation has become the process $d u$ jour in the military. It is being pushed by everyone from the Commander-in-Chief to second lieutenants. Concurrently, the global 
war on terrorism continues in addition to ongoing deployments to locations such as Iraq, Afghanistan, Kosovo, and Bosnia. How does the military effect massive organizational change while actively fighting a war?

2. The war in Afghanistan offered an example of using proxy forces, in this case the Northern Alliance, to fight a war. What kind of leadership is required to motivate local forces to fight on behalf of a third party?

3. We know technology changes the nature of leadership (Avolio, Kahai, \& Dodge, 2000), yet the quantum leaps in technology in the military are outpacing what we know about the effects of technology on leadership. Technology allows the leader to be halfway across the globe from the followers, deluges the leader with information, brings visibility to previously obscured leadership levels, and shortens decision times to nanoseconds. Research opportunities in this area are both plentiful and urgent.

4. Effectiveness in battle is easily measured. However, how is effectiveness assessed in operations such as peacekeeping, humanitarian assistance, or disaster relief? What metric should military leaders use to measure unit effectiveness in the garrison environment?

5. As the military increasingly shifts to a joint force, the subcultures of the Army, Navy, Air Force, and Marines are diluted. Leadership scholars should examine the interaction of subcultures and the emergence of a joint culture. Particular emphasis should be placed on how leaders in joint positions react when conflict arises with their parent service.

6. Finally, the concept of embedding media into units in combat appears to have garnered wide acceptance. Is such a concept possible for leadership researchers? Are there leadership researchers who would be willing to accompany a unit into battle in order to collect data? Would the military be amenable to this twist on the embedded concept?

Today's military is an interesting blend of tradition and change. With the advent of the all-volunteer force, the military has moved from near collapse in the post-Vietnam era to a high quality institution that can handle any national crisis ranging from battling forest fires to driving into Baghdad. Leadership remains inextricably intertwined with the military at every level. It is our hope that this article piques the interest of leadership scholars to look into this institution called the military. We believe they will find ample opportunities to further the field of leadership in general and military leadership in particular.

\section{References}

Armor, D. J. (1996). Race and gender in the U.S. military. Armed Forces And Society, 23, 7-27.

Avant, D. (2002). Privatizing military training: A challenge to U.S. Army professionalism? In D. M. Snider, G. L. Watkins, \& L. J. Matthews (Eds.), The future of the army profession (pp. 179-196). New York: McGraw-Hill. Avolio, B. J., Kahai, S., \& Dodge, G. E. (2000). E-leadership: Implications for theory, research, and practice. Leadership Quarterly, 11, 615-668. 
Bacevich, A. J., \& Kohn, R. H. (1997). Grand army of the Republicans: Has the U.S. military become a partisan force? New Republic, 217, 22-25.

Bartone, P. T., Snook, S. A., \& Tremble, T. R. (2002). Cognitive and personality predictors of leader performance in West Point cadets. Military Psychology, 14, 321-338.

Bartunek, J. M., \& Necochea, R. (2000). Old insights and new times: Kairos, Inca cosmology and their contributions to contemporary management inquiry. Journal of Management Inquiry, 9(2), 103-113.

Bass, B. M. (1985). Leadership and performance beyond expectations. New York, NY: Free Press.

Bass, B. M. (1998). Transformational leadership: Industrial, military, and educational impact. Mahwah, NJ: Erlbaum.

Bass, B. M., Avolio, B. J., Jung, D. I., \& Berson, Y. (2003). Predicting unit performance by assessing transformational and transactional leadership. Journal of Applied Psychology, 88(2), 207-218.

Beaumont, R. (1993). Joint military operations: A short history. Westport, CT: Greenwood Press.

Biernat, M. B., Manis, M., \& Nelson, T. E. (1991). Stereotypes and standards of judgment. Journal of Personality and Social Psychology, 60, 485-499.

Biernat, M., Crandall, C. S., Young, L. V., Kobrynowicz, D., \& Halpin, S. M. (1998). All that you can be: Stereotyping of self and others in a military context. Journal of Personality and Social Psychology, 75, 300-317.

Black, J. A., \& Boal, K. B. (1996). Assessing the organizational capacity to change. In A. Heene, \& R. Sanchez (Eds.), Competence-based strategic management (pp. 151-158). Chichester, UK: Wiley.

Blair, J. D., \& Hunt, J. G. (1986). Getting inside the head of the management researcher one more time: Contextfree and context-specific orientations in research. Yearly Review of Management, 12(2), 147-166.

Bliese, P. (2000). Within-group agreement, non-independence, and reliability. In K. Klein, \& S. Kozlowski (Eds.), Multi-level theory, research, and methods in organizations (pp. 349-381). San Francisco, CA: Jossey-Bass.

Bliese, P. D., \& Britt, T. W. (2001). Social support, group consensus and stressor-strain relationships: Social context matters. Journal of Organizational Behavior, 22, 425-436.

Bliese, P. D., \& Castro, C. A. (2000). Role clarity, work overload and organizational support: Multilevel evidence of the importance of support. Work and Stress, 14, 65-73.

Bliese, P. D., \& Halverson, R. R. (1996). Individual and nomothetic models of job stress: An examination of work hours, cohesion, and well-being. Journal of Applied Social Psychology, 26, 1171-1189.

Bliese, P. D., \& Halverson, R. R. (1998). Group consensus and psychological well-being: A large field study. Journal of Applied Social Psychology, 28, 563-580.

Bliese, P. D., Halverson, R. R., \& Rothberg, J. M. (2002). Within-group agreement scores: Using resampling procedures to estimate expected variance. Academy of Management Best Paper, 303-307.

Bliese, P. D., Halverson, R. R., \& Schriesheim, C. A. (2002). Benchmarking multilevel methods: Comparing HLM, WABA, SEM, and RGR. Leadership Quarterly, 13, 3-14.

Boal, K. B., \& Hooijberg, R. (2001). Strategic leadership research: Moving on. Leadership Quarterly, 11, 515-549.

Bourgeois III, L. J. (1985). Strategic goals, perceived uncertainty, and economic performance in volatile environments. Academy of Management Journal, 28, 548-573.

Bradley, J. P., Nicol, A. A. M., Charbonneau, D., \& Meyer, J. P. (2002). Personality correlates of leadership development in Canadian forces officer candidates. Canadian Journal of Behavioral Science, 34, 92-103.

Briscoe, J. P., \& Hall, D. T. (1999). Grooming and picking leaders using competency frameworks: Do they work? An alternative approach and new guidelines for practice. Organizational Dynamics, 28(2), 37-52.

Buckingham, C. T. (1995). Ethics and the senior officer: Institutional tensions. Parameters, 25(2), 98-110.

Bunker, R. J. (1998). Information operations and the conduct of land warfare. Military Review, 78, 4-17.

Burnett, J. (2003). Embedded/unembedded II. Columbia Journalism Review, 42, 43-44.

Bush, G. W. (2001). Address to U.S. Naval Academy. Available at: http://www.whitehouse.gov/news/releases/ 2001/05/20010525-1.html.

Campbell, J. P. (1999). The definition and measurement of performance in the new age. In D. R. Ilgen, \& E. D. Pulakos (Eds.), The changing nature of performance: Implications for staffing, motivation, and development. San Francisco: Jossey-Bass. 
Cebrowski, A. K., \& Garstka, J. J. (1998). Network centric warfare: Its origin and future. Proceedings of the Naval Institute, 124, 28-35.

Chan, K. Y., \& Drasgow, F. (2001). Toward a theory of individual differences and leadership: Understanding the motivation to lead. Journal of Applied Psychology, 86, 481-498.

Chemers, M. M. (2000). Leadership research and theory: A functional integration. Group Dynamics, 4, $27-43$.

Chen, G., \& Bliese, P. D. (2002). The role of different levels of leadership in predicting self and collective efficacy: Evidence for discontinuity. Journal of Applied Psychology, 87, 549-556.

Cohen, W. M., \& Levinthal, D. A. (1990). Absorptive capacity: A new perspective on learning and innovation. Administrative Science Quarterly, 35, 128-152.

Connelly, M. S., Gilbert, J. A., Zaccaro, S. J., Threlfall, K. V., Marks, M. A., \& Mumford, M. D. (2000). Exploring the relationship of leadership skills and knowledge to leader performance. Leadership Quarterly, $11,65-86$.

Cook, M. L. (2000). Moral foundations of military service. Parameters, 30(1), 117-129.

Cook, M. L. (2002). Ethical issues in counterterrorism warfare. In J. R. Martin (Ed.), Defeating terrorism: Strategic issue analyses (pp. 71-74). Carlisle, PA: Strategic Studies Institute.

Csoka, L. S., \& Bons, P. M. (1978). Manipulating the situation to fit the leader's style: Two validation studies of LEADER MATCH. Journal of Applied Psychology, 63, 295-300.

Day, D. V., \& Lord, R. G. (1988). Executive leadership and organizational performance: Suggestions for a new theory. Journal of Management, 14, 453-464.

de Torrente, N. (2001). Congressional testimony of the Executive Director, Médecins Sans Frontières USA. Washington, DC. October 10. http://www.doctorswithoutborders.org/publications/speeches/2001/ ndt_afghanistan.shtml.

Deluga, R. J. (1991). The relationship of leader and subordinate influencing activity in naval environments. Military Psychology, 3, 25-39.

Dorn, E., \& Graves, H. D. (2000). American military culture in the twenty-first century: A report of the CSIS International Security Program. Washington, DC: Center for Strategic and International Studies.

Dunlap Jr., C. J. (2000). The origins of the American military coup of 2012. Parameters, 2-20.

Durning, K. P. (1978). Women at the naval academy. Armed Forces and Society, 4, 569-588.

Dvir, T., Eden, D., Avolio, B. J., \& Shamir, B. (2002). Impact of transformational leadership on follower development and performance: A field experiment. Academy of Management Journal, 45, 735-744.

Ethiel, N. (2000). The military and the media: Facing the future. Wheaton, IL: Tribune McCormick Foundation.

Festinger, L. (1954). A theory of social comparison processes. Human Relations, 7, 117-140.

Gailbreath, R. D., Wagner, S. L., Moffett, R. G., \& Hein, M. B. (1997). Homogeneity in behavioral preferences among U.S. army leaders. Group Dynamics, Theory, Research, and Practice, 1, 222-230.

Gegax, T. T. (2003). Wired for battle. Newsweek, 141, 32.

Gilmore, G. J. (2003). 'Transformation means profound change,' Wolfowitz tells NWC grads. American Forces Press Service. Available at: http://www.defenselink.mil/news/Jun2003/n06202003_200306203.html.

Gordon, R. D. (2002). Conceptualizing leadership with respect to its historical-contextual antecedents to power. Leadership Quarterly, 13, 151-167.

Gould, J. B. (2002). Playing with fire: The civil liberties implications of September 11th. Public Administration Review, 62, 74-79.

Harris Poll (2003, January 22). Harris confidence index.

Harris, P., \& Lucas, K. W. (1991). Executive leadership: Requisite skills and developmental process for three- and four-star assignments. Alexandria, VA: U.S. Army Research Institute for the Behavioral and Social Sciences.

Hedlund, J., Forsythe, G. B., Horvath, J. A., Williams, W. M., Snook, S., \& Sternberg, R. J. (2003). Identifying and assessing tacit knowledge: Understanding the practical intelligence of military leaders. Leadership Quarterly, 14, 117-140.

Hillen, J. (1999). Must U.S. military culture reform? Orbis, 43(1), 43-57.

Hodges, J. S. (1994). Analytic use of data from Army training exercises: A case study of tactical reconnaissance. Journal of the American Statistical Association, 89, 444-451. 
Holland, W. J. (2003). What really lies behind the screen? Proceedings, Unites States Naval Institute, 129, $73-77$. Holsti, O. R. (1998). A widening gap between the U.S. military and civilian society? Some evidence, 1976-1996. International Security, 23, 5-42.

Holsti, O. R. (2001). Of chasms and convergences: Attitudes and beliefs of civilians and military elites at the start of a new millennium. In P. D. Feaver, \& R. H. Kohn (Eds.), Soldiers and civilians: The civil-military gap and American national security (pp. 15-99). Cambridge, MA: MIT Press.

Hooijberg, R., Bullis, R. C., \& Hunt, J. G. (1999). Behavioral complexity and the development of military leadership for the twenty-first century. In J. G. Hunt, G. E. Dodge, \& L. Wong (Eds.), Out-of-the-box leadership: Transforming the twenty-first-century army and other top performing organizations (pp. 111-130). Greenwich, CT: JAI Press.

Hooijberg, R., \& Quinn, R. E. (1992). Behavioral complexity and the development of effective managers. In R. L. Phillips, \& J. G. Hunt (Eds.), Strategic leadership: A multiorganizational-level perspective. Westport, CT: Quorum.

House, R. J. (1977). A 1976 theory of charismatic leadership. In J. G. Hunt, \& L. Larson (Eds.), Leadership: The cutting edge. Carbondale, IL: Southern Illinois University Press.

House, R. J. (1996). Path-goal theory of leadership: Lesson, legacy, and a reformulated theory. Leadership Quarterly, 7, 323-352.

Hunt, J. G. (1991). Leadership: A new synthesis. Newbury Park, CA: Sage.

Hunt, J. G., \& Phillips, R. L. (1991). Leadership in battle and garrison: A framework for understanding the differences and preparing for both. In R. Gal, \& D. Mangelsdorff (Eds.), Handbook of military psychology (pp. 411-429). Chichester, UK: Wiley.

Huntingdon, S. P. (1957). The soldier and the state: The theory and politics of civil-military relations. Cambridge, MA: Harvard University Press.

Institute of Politics, Harvard University (2002). A national survey of college undergraduates. Cambridge, MA: Harvard University.

Isaacson, J. A., Layne, C., \& Arquilla, J. (1999). Predicting military innovation. Santa Monica, CA: RAND.

Jablonsky, D. (2001). Army transformation: A tale of two doctrines. In C. Crane (Ed.), Transforming defense. Carlisle, PA: Strategic Studies Institute.

Jacobs, T. O., \& Jaques, E. (1990). Military executive leadership. In K. E. Clark, \& M. B. Clark (Eds.), Measures of leadership (pp. 281-296). West Orange, NJ: Leadership Library of America.

James, L. R., Demaree, R. G., \& Wolf, G. (1984). Estimating within-group interrater reliability with and without response bias. Journal of Applied Psychology, 69, 85-98.

James, L. R., Demaree, R. G., \& Wolf, G. (1993). RWG: An assessment of within-group interrater agreement. Journal of Applied Psychology, 78, 306-309.

Janowitz, M. (1960). The professional soldier: A social and political portrait. New York: Free Press.

Jantzen, L. C. (2001). Taking charge of technology. Military Review, 81, 73-79.

Jaques, E. (1976). A general theory of bureaucracy. Exeter, NH: Heinemann.

Jaques, E. (1989). Requisite organization. Arlington, VA: Cason Hall.

Jaques, E., \& Clement, S. D. (1991). Executive leadership: A practical guide to managing complexity. Arlington, VA: Cason Hall.

Jaques, E., Clement, S., Rigby, C., \& Jacobs, T. O. (1986). Senior leadership requirements at the executive level. Alexandria, VA: U.S. Army Research Institute for the Behavioral and Social Sciences.

Johnson Jr., D. V., \& Metz, S. (1995). American civil-military relations: New issues, enduring problems. Carlisle, PA: Strategic Studies Institute.

Judge, T. A., Bono, J. E., Ilies, R., \& Gerhardt, M. W. (2002). Personality and leadership: A qualitative and quantitative review. Journal of Applied Psychology, 87, 765-780.

Kahn, P. W. (2002). The paradox of riskless warfare. Paper presented at the Moral Dimensions of American Military Strategy Conference, Carlisle, PA.

Kegan, R. (1982). The evolving self: Problem and process in human development. Cambridge, MA: Harvard University Press. 
Kellerman, B. K., \& Webster, S. W. (2001). The recent literature on public leadership: Reviewed and considered. Leadership Quarterly, 12, 485-514.

Kitfield, J. (1998). Standing apart. National Journal, 3, 1350-1358.

Kohn, R. H. (1994). Out of control: The crisis in civil-military relations. National Interest, 35, 3-17.

Lehman, J. (1994). An exchange on civil-military relations. National Interest, 36, 24.

Lewis, L., Brown, R. A., \& Roll, C. R. (2001). Service responses to the emergence of joint decisionmaking. Santa Monica, CA: RAND.

Lewis, P., \& Jacobs, T. O. (1992). Individual differences in strategic leadership capacity: A constructive/developmental view. In R. L. Phillips, \& J. G. Hunt (Eds.), Strategic leadership: A multiorganizational-level perspective (pp. 121-137). Westport, CT: Quorum Books.

Lord, R. G., \& Hall, R. J. (1992). Contemporary views of leadership and individual differences. Leadership Quarterly, 3, 137-157.

Lovelace, D. C. (1996). Unification of the United States armed forces: Implementing the 1986 Department of Defense Reorganization Act. Carlisle, PA: Strategic Studies Institute.

Lucas, K. W., \& Markessini, J. (1993). Senior leadership in a changing world order: Requisite skills for U.S. army one- and two-star generals. Alexandria, VA: U.S. Army Research Institute for the Behavioral and Social Sciences.

Magee, R. R. (1998). Strategic leadership primer. Carlisle, PA: U.S. Army War College.

Malan, L. C., \& Kriger, M. P. (1998). Making sense of managerial wisdom. Journal of Managerial Inquiry, 7 , $242-251$.

Markessini, J., Lucas, K. W., Chandler, N., \& Jacobs, T. O. (1994). Executive leadership: Requisite skills and developmental processes for the U.S. Army's civilian executives. (ARI Research Note 94-26). Alexandria, VA: U.S. Army Institute for the Behavioral and Social Sciences.

Masters, J. K. (2002). Predicting the use of external labor arrangements: A test of the transaction costs perspective. Academy of Management Journal, 45(2), 431.

McCormack, L., \& Mellor, D. (2002). The role of personality in leadership: An application of the five-factor model in the Australian military. Military Psychology, 14, 179-197.

McCormick, D. (1998). The downsized warrior: America's army in transition. New York: New York University Press.

McGee, M. L., Jacobs, T. O., Kilcullen, R. N., \& Barber, H. F. (1999). Conceptual capacity as competitive advantage: Developing leaders for the new army. In J. G. Hunt, G. E. Dodge, \& L. Wong (Eds.), Out-ofthe-box leadership: Transforming the twenty-first-century army and other top-performing organizations (pp. 221-238). Stamford, CT: JAI Press.

Meindl, J., \& Ehrlich, S. (1987). The romance of leadership and the evaluation of organizational performance. Academy of Management Journal, 30(1), 91-109.

Mintzberg, H. (1973). The nature of managerial work. New York: Harper and Row.

Morris, M. (1996). By force of arms: Rape, war and military culture. Duke Law Journal, 45, 651-781.

Moskos, C. (2000). The media and the military in peace and humanitarian operations. Wheaton, IL: Tribune McCormick Foundation.

Mumford, M. D., Marks, M. A., Connelly, M. S., Zaccaro, S. J., \& Reiter-Palmon, R. (2000). Development of leadership skills: Experience and timing. Leadership Quarterly, 11, 87-144.

Mumford, M. D., Zaccarro, S. J., Johnson, J. F., Diana, M., Gilbert, J. A., \& Threlfall, K. V. (2000). Pattern of leader characteristics: Implications for performance and development. Leadership Quarterly, 11, 115-133.

Murray, S. F. (2002). Battle command, decisionmaking, and the battlefield panopticon. Military Review, 82, $46-51$.

Myers, I. B., \& McCaulley, M. H. (1985). Manual: A guide to the development and use of the Myers-Briggs Type Indicator. Palo Alto, CA: Consulting Psychologists Press.

Pape, M. S. (2002). Can we put the leaders of the "axis of evil" in the crosshairs? Parameters, 32(3), 62-71.

Pershing, J. (2001). Gender disparities in enforcing the honor concept at the U.S. Naval Academy. Armed Forces and Society, 27, 419-442. 
Pfeffer, J. (1977). The ambiguity of leadership. Academy of Management Review, 2, 104-112.

Phillips, R. L., \& Wong, L. (1990). An integrated model of military unit effectiveness. Proceedings of the Southern Management Association, Orlando, FL.

Pulakos, E. D., Arad, S., Donovan, M. A., \& Plamondon, K. E. (2000). Adaptability in the workplace: Development of a taxonomy of adaptive performance. Journal of Applied Psychology, 85, 612-624.

Quinn, R. E. (1988). Beyond rational management: Mastering the paradoxes and competing demands of high performance. San Francisco: Jossey-Bass.

Rice, R. W., Instone, D., \& Adams, J. (1984). Leader sex, leader success, and leadership process: Two field studies. Journal of Applied Psychology, 69, 12-31.

Ricks, T. E. (1997). Making the corp: Sixty-one men came to Parris Island to become marines, not all of them made it. New York: Scribner.

Rosen, L. N., Knudson, K. H., \& Fancher, P. (2003). Cohesion and the culture of hypermasculinity in U.S. army units. Armed Forces and Society, 29, 325-351.

Roush, P. E., \& Atwater, L. (1992). Using the MBTI to understand transformational leadership and self-perception accuracy. Military Psychology, 4, 17-34.

Schneider, B. (1987). The people make the place. Personnel Psychology, 40, 437-453.

Schneider, B., Goldstein, H. W., \& Smith, D. B. (1995). The ASA framework: An update. Personnel Psychology, 48, 747-773.

Segal, M. W. (1988). The military and the family as greedy institutions. In C. C. Moskos, \& F. R. Woods (Eds.), The military: More than just a job? (pp. 79-97). Washington, DC: Pergamon-Brassey.

Seib, P. (2002). The global journalist: News and conscience in a world of conflict. Lanham, MD: Rowman and Littlefield.

Shamir, B., Goldberg-weill, B., Breinin, E., Zakay, E., \& Popper, M. (2000). Differences in company leadership between infantry and armor units in the Israel defense forces. Military Psychology, 12, 51-72.

Shamir, B., Zakay, E., Breinin, E., \& Popper, M. (1998). Correlates of charismatic leader behavior in military units: Subordinates' attitudes, unit characteristics, and superior appraisals of leader performance. Academy of Management Journal, 41, 387-409.

Shanker, T. (1998). Army is designing ways to reorganize its forces. New York Times.

Smolkin, R. (2003). Media mood swings. American Journalism Review, 25, 16-23.

Snider, D. M. (1999). An uninformed debate on military culture. Orbis, 43, 11-26.

Snider, D. M. (2003). Jointness, defense transformation, and the need for a new joint warfare profession. Parameters, 33(2), 17-30.

Snider, D. M., \& Watkins, G. L. (2002). The future of the army profession. New York: McGraw-Hill.

Steele, W. M., \& Walters Jr., R. P. (2001). 21st century leadership competencies. Army, 51, 29-32.

Steinberg, A. G., \& Foley, D. M. (1999). Mentoring in the army: From buzzword to practice. Military Psychology, $11,365-379$.

Sullivan, G. R., \& Harper, M. V. (1996). Hope is not a method: What business leaders can learn from America's army. New York: Times Business.

Thomas, J. L., Dickson, M. W., \& Bliese, P. D. (2001). Using personal values and motives to predict success as a leader in the US Army Reserve Officer Training Corps. Leadership Quarterly, 12, 181-196.

U.S. Army (1970). Study on military professionalism. Carlisle, PA: U.S. Army War College.

U.S. Army (1990a). Field Manual 22-100, Army leadership. Washington, DC: U.S. Government Printing Office.

U.S. Army (1990b). Field Manual 25-101, Battle focused training. Washington, DC: U.S. Government Printing Office.

U.S. Army (1996). The Secretary of the army's task force on extremist activities. Washington, DC: U.S. Government Printing Office.

U.S. Army (1997a). Senior review panel report on sexual harassment. Washington, DC: U.S. Government Printing Office.

U.S. Army (1997b). The Human dimensions of combat readiness. Washington, DC: U.S. Government Printing Office. 
U.S. Army (1999a). U.S. army vision statement. Available at: http://www.army.mil/vision/Documents/The\%20Army\%20Vision.PDF.

U.S. Army (1999b). Field Manual 22-100, Army leadership. Washington, DC: U.S. Government Printing Office.

U.S. Army (2000). Readiness reporting in the U.S. army. Carlisle, PA: U.S. Army War College.

U.S. Army (2001a). Field Manual 3, operations. Washington, DC: U.S. Government Printing Office.

U.S. Army (2001b). The army training and leader development panel officer study report to the army. Available at: http://www.army.mil/features/ATLD/report.pdf.

U.S. Army (2001c). U.S. army white paper: Concepts for the objective force. Available at: http://www.objectiveforce.army.mil/key\%20Docs/white_paper.htm.

U.S. Department of Defense (2000). Population representation in the military services. Washington, DC: U.S. Government Printing Office.

U.S. Department of Defense (2001). Network centric warfare. Washington, DC: U.S. Government Printing Office.

U.S. Government Accounting Office (1993). Joint military operations: DoD's renewed emphasis on interoperability is important but not adequate. Washington, DC: U.S. Government Printing Office.

U.S. Joint Forces Command (2003). United States joint forces command briefing. Norfolk, VA: JFCOM.

Vecchio, R. P., \& Bullis, R. C. (2001). Moderators of the influence of supervisor-subordinate similarity on subordinate outcomes. Journal of Applied Psychology, 86, 884-896.

Wayne, L. (2003). America's for-profit secret army. New York Times, 1.

Wong, L. (2000). Generations apart: Xers and boomers in the officer corps. Carlisle, PA: Strategic Studies Institute.

Wong, L. (2001). Stifling innovation: Developing tomorrow's leaders today. Carlisle, PA: Strategic Studies Institute.

Wong, L., \& McNally, J. (1994). Downsizing the army: Some policy implications affecting the survivors. Armed Forces and Society, 20, 199-216.

Wong, L., Kolditz, T. A., Millen, R. A., \& Potter, T. M. (2003). Why they fight: Combat motivation in the Iraq War. Carlisle, PA: Strategic Studies Institute.

Zaccaro, S. J. (1996). Models and theories of executive leadership: A conceptual/empirical review and integration. Alexandria, VA: Army Research Institute for the Behavioral Sciences.

Zaccaro, S. J., Gilbert, J. A., Thor, K. K., \& Mumford, M. D. (1991). Leadership and social intelligence: Linking social perceptiveness and behavioral flexibility to leader effectiveness. Leadership Quarterly, 2, 317-342. 